The Relationship Between Social Functioning and Resilience in Young People with Conduct Problems and Callous-Unemotional Traits.

$$
\text { By }
$$

\title{
Caitlin Heesterman
}

\begin{abstract}
A thesis submitted to the Victoria University of Wellington in fulfilment of the requirements for the degree of Master of Science in Forensic Psychology
\end{abstract}

Victoria University of Wellington 2021 
SOCIAL FUNCTIONING \& RESLIENCE IN YOUNG PEOPLE 


\begin{abstract}
Resilience is the dynamic process of achieving positive outcomes in the presence of risk or difficulties. For young people, greater social functioning tends to increase resilience as individuals benefit from the support of family, peers and any teachers or adults around them. Additionally, these relationships provide young people an opportunity to practice skills which might also contribute to better outcomes (e.g., learning how to collaborate effectively). The current study investigated how the association between resilience and each of peer relationships, collaboration, perspective taking, empathic concern and prosocial behaviour was different across four groups of adolescent participants with high and low callousunemotional $(\mathrm{CU})$ traits and/or conduct problems $(\mathrm{CP})$. Individuals varying on $\mathrm{CU}$ and $\mathrm{CP}$ tend to have reduced social functioning, reduced resilience and be at risk for worse long-term outcomes. A multiple regression analysis showed that as these social functioning variables increased, so did resilience for all groups other than those high on CP alone. Significant predictors within the model varied depending on whether individuals were high on both, one or neither of $\mathrm{CU}$ and $\mathrm{CP}$. Collaboration, prosocial behaviour and peer relationships were all significant predictors of resilience for individuals low on both difficulties, whereas collaboration was the only significant predictor those only high on callous-unemotional traits. Prosocial behaviour was the only significant predictor for those high on both difficulties. These results suggest the importance of considering how these difficulties interact as greater resilience might be fostered in different ways depending on the unique pattern individuals exhibit of callous-unemotional traits and conduct problems.
\end{abstract}


SOCIAL FUNCTIONING \& RESLIENCE IN YOUNG PEOPLE 


\section{Acknowledgements}

Firstly, I would like to thank my supervisor, Dr Hedwig Eisenbarth, for your guidance and support throughout this, and the other projects we have worked on together since I started working with you in 2018. Your belief in me and patience with me throughout this time is deeply appreciated. Because of you, I have developed a love for high quality research as well as learnt how to be more compassionate to myself - thank you. I would also like to thank the Affective and Criminal Neuroscience Lab for the feedback and support throughout 2020.

Thank you to my fellow students, both in the Forensic Master's degree and in the Clinical Programme. A particular thank you goes to Emerald, who shared an office with me, and the girls in the office next door (Amelia, Annalise, Charlotte and Annette) who have journeyed with me over the past two years to completing this degree. I would not have got by without the coffee, wine and friendship we've shared. Your passion inspires me.

I would also like to thank Ella. Together, you and I have done research, attended conferences, travelled overseas, learnt to surf $\&$ much more. It has been a tremendous pleasure studying alongside you for the past few years - you have made a long road through the university system, not only survivable but enjoyable.

And finally, thank you to Hayden, you have seen me in all stages of this project. Thank you for picking me up from late nights in the office, bringing me dinner and whisking me away from the university when I've needed it. You remind me that I am loved not for what I can achieve but for who I am. 
SOCIAL FUNCTIONING \& RESLIENCE IN YOUNG PEOPLE 


\section{Table of Contents}

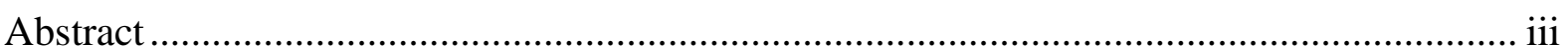

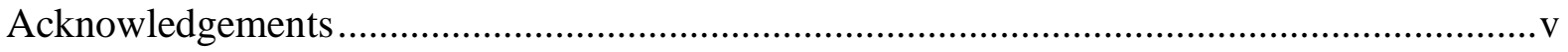

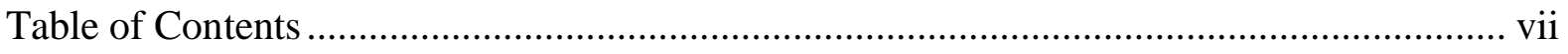

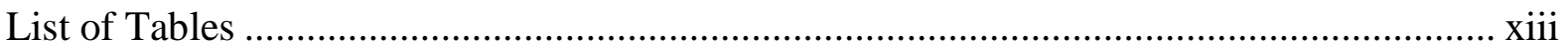

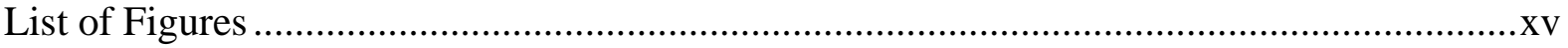

List of Acronyms, Abbreviations and Key Terms ........................................................... xvii

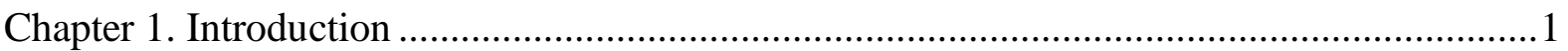

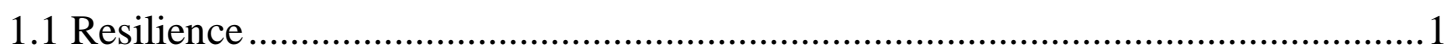

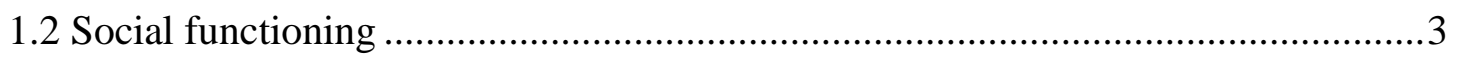

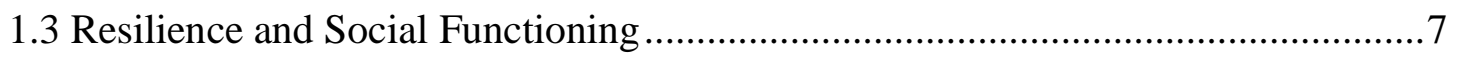

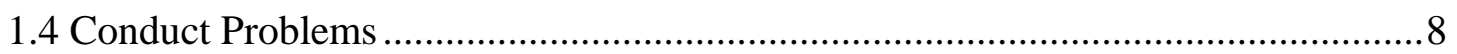

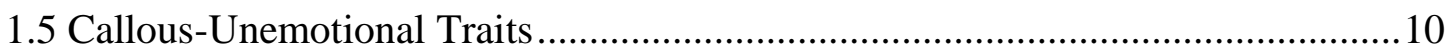

1.6 Subtypes of Callous Unemotional Traits and Conduct Problems..........................12

1.7 Social Functioning in Callous-Unemotional Traits and Conduct problems ..........15

1.8 Resilience, Conduct Problems and Callous-Unemotional traits ...........................17

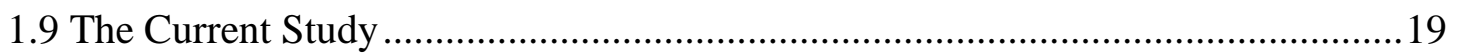

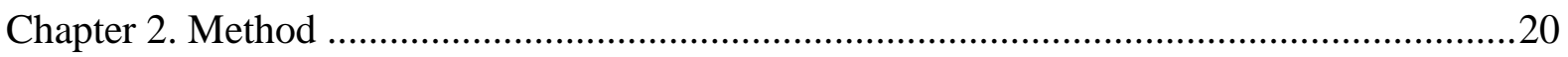

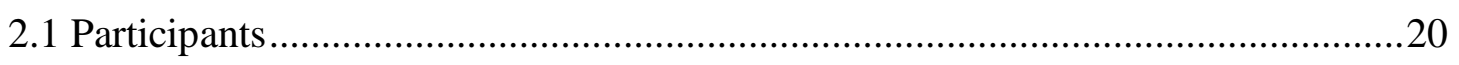

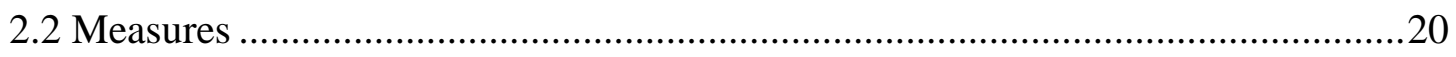


SOCIAL FUNCTIONING \& RESLIENCE IN YOUNG PEOPLE 


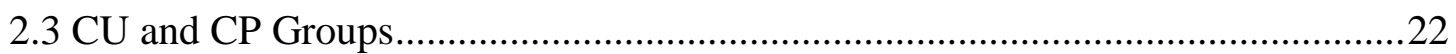

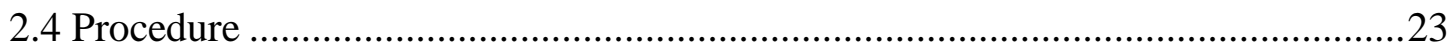

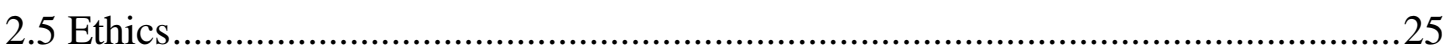

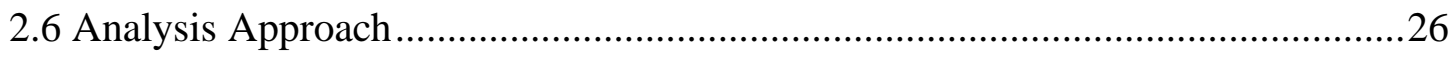

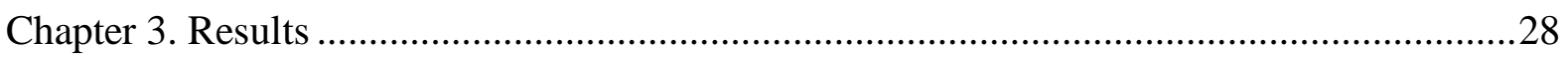

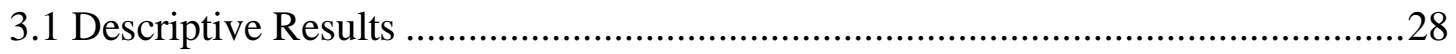

3.2. Correlations Between Social Functioning and Resilience by Group ...................22

3.3 Multiple Regression Model by Group ............................................................ 33

3.4 Exploratory Validity Analysis for the IRI Questionnaire ....................................37

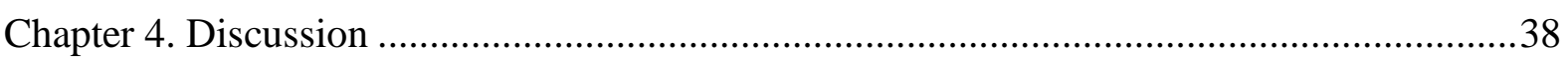

4.1 Pattern of Strong Results for High Callous-Unemotional Traits Low Conduct

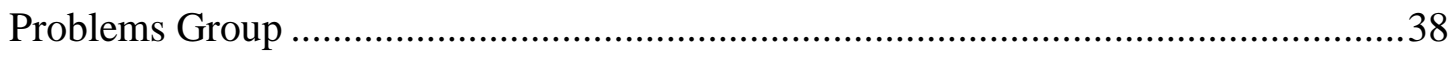

4.2 The Role of Collaboration in Resilience .........................................................4

4.3 Perspective Taking and the Interpersonal Reactivity Index ...............................42

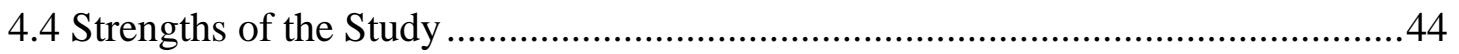

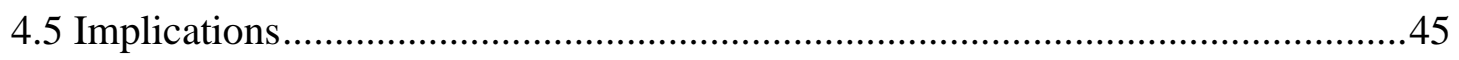

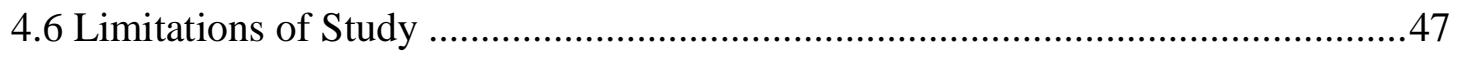

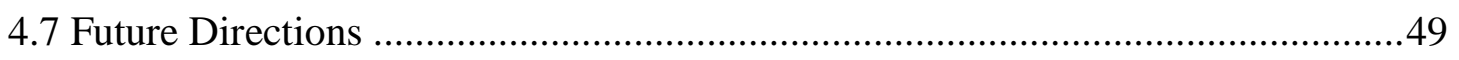

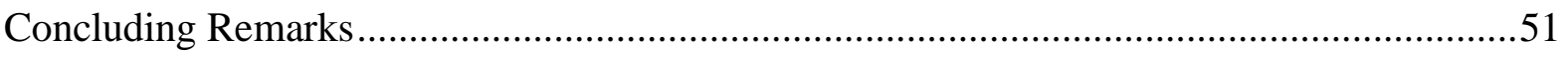

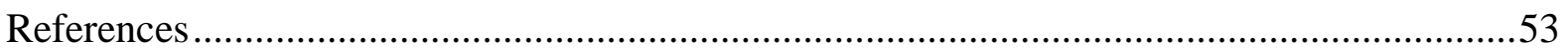


SOCIAL FUNCTIONING \& RESLIENCE IN YOUNG PEOPLE 
Appendix D. Standardised Instructions for Staff to Read to the Student's Pre-

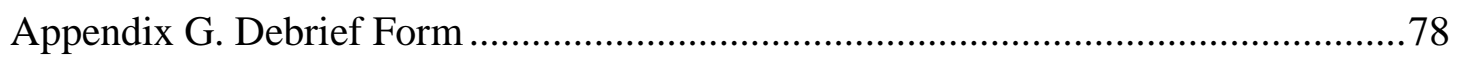

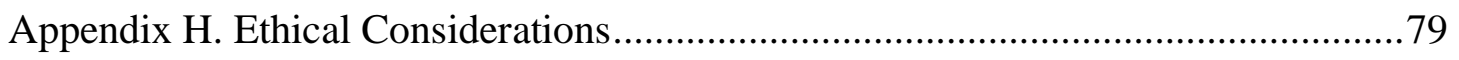

Appendix I. Comparison of Model 1 and Model $2 R^{2}$ For Groups. 
SOCIAL FUNCTIONING \& RESLIENCE IN YOUNG PEOPLE 
List of Tables

Table 1 Group Comparisons for CU \& CP

Table 2 Correlation Matrix for All Variables

Table 3 Group Comparisons for Social Functioning Variables and Resilience

Table $4 \quad$ Model 1 and Model 2 Multiple Regressions for All Four Groups

Table 5 Comparison of Confirmatory Factor Analysis Fit for the Four-Factor Model of the IRI

Table 6 Comparison of $R^{2}$ Values Across Groups for Both Model 1 and Model 2 and Between Model 1 and Model 
SOCIAL FUNCTIONING \& RESLIENCE IN YOUNG PEOPLE 
List of Figures

Figure $1 \quad$ Intersection of CU Traits and CP to Form Groups

Figure 2 Group Comparisons for CU and CP Levels

Figure $3 \quad$ Multiple Regression Employed in Current Study (Model 1)

Figure 4 Correlations Between Empathic Concern \& Resilience Across CU \& CP Groups

Figure 5 Correlations Between Perspective Taking \& Resilience Across CU \& CP Groups

Figure 6 Correlations Between Prosocial Behaviour \& Resilience Across CU \& $\mathrm{CP}$

Figure 7 Correlations Between Collaboration \& Resilience Across CU \& CP Groups

Figure 8 Correlations Between Peer Relationships (-) \& Resilience Across CU \& CP Groups 
SOCIAL FUNCTIONING \& RESLIENCE IN YOUNG PEOPLE 
SOCIAL FUNCTIONING \& RESLIENCE IN YOUNG PEOPLE

List of Acronyms, Abbreviations and Key Terms

$\mathrm{AL}$

$\mathrm{AO}$

$\mathrm{CD}$

$\mathrm{CP}$

$\mathrm{CU}$

CYRM-12

CL

EOP

$\mathrm{H}_{\mathrm{CU}} \mathrm{H}_{\mathrm{CP}}$

$\mathrm{H}_{\mathrm{CU}} \mathrm{L}_{\mathrm{CP}}$

$\mathrm{LCU}_{\mathrm{CU}} \mathrm{H}_{\mathrm{CP}}$

$\mathrm{LCU}_{\mathrm{CP}}$

ICU

IRI

SDQ
Adolescent Limited

Adolescent Onset

Conduct Disorder

Conduct Problems

Callous-Unemotional traits

Child and Youth Resilience Measure - 12 Item

Childhood Limited

Early Onset Persistent

High on both Callous Unemotional traits and Conduct Problems

High on Callous Unemotional traits and Low on Conduct

Problems

Low on Callous Unemotional traits and High on Conduct

Problems

Low on Both Callous Unemotional traits and Conduct Problems

Inventory of Callous-Unemotional traits

Interpersonal Reactivity Index

Strengths and Difficulties Questionnaire 
SOCIAL FUNCTIONING \& RESLIENCE IN YOUNG PEOPLE 
SOCIAL FUNCTIONING \& RESLIENCE IN YOUNG PEOPLE

\section{Chapter 1. Introduction}

Resilience is a feature of clinical interest within psychology due to how it enables individuals to overcome adversity and achieve better outcomes. It is for this reason that understanding what drives greater resilience and how resilience can be strengthened is also of clinical interest. Moreover, understanding whether resilience can be enhanced and how, helps with mitigating the effects of this adversity. Additionally, resilience, which by its nature is a dynamic process, does not occur in the same manner for all people. It is for this reason that resilience and factors that are related to greater resilience should be studied, with focus on the nuances of how it varies across populations and groups. This is the aim of the current study; to understand how measures of social functioning relate to resilience and how this relationship may vary across different groupings of young people with callous-unemotional traits $(\mathrm{CU})$ and conduct problems $(\mathrm{CP})$.

\subsection{Resilience}

Resilience is the developmental process of achieving positive outcomes in the presence of difficulties (Luthar et al., 2000; Khanlou \& Wray, 2014; Vella \& Nagesh, 2019). By defining resilience as a process, the focus becomes on resilience being a series of mechanisms rather than being an accumulation of static protective factors or a personality trait (Luthar \& Cicchetti, 2000). Resilience is also multileveled; occurring within a biopsychosocial context. This implicates systems at the neurobiological level, the individual psychological or emotional level and at the environmental-systemic and social levels of human functioning (Herrman et al., 2011; Vella \& Nagesh, 2019). The environmentalsystemic level can be further split into micro-environment, which includes factors such as family relations, attachment, peer support, workplaces, clubs or groups someone is involved in, and the macro-environment including factors such as equality, opportunity/access to education/health, or spirituality. These levels are not necessarily distinct and indeed some 


\section{SOCIAL FUNCTIONING \& RESLIENCE IN YOUNG PEOPLE}

systems may occur across several levels. For example, self-esteem is a psychological phenomenon which works as a protective mechanism. Self-esteem may be shaped by experiences in the social world such as supportive friendships or bullying. However, selfesteem may also be shaped by the social context in which biological or neurological conditions occur. For example, a specific learning disorder may lead to a child falling behind in school and in turn becoming self-conscious about their achievement. Whilst in this example the specific learning disorder does not biologically cause the lowered self-esteem, they are linked experiences. In this way, the levels in which resilience mechanisms occur, interact with one another and, as such, all levels of resilience must all be considered in research and practice.

It is also important to consider how and where the positive outcome, that occurs in spite of adversity, is measured. Resilience does not necessitate positive outcomes in all domains, nor does showing positive outcomes in one domain but not another imply a lack of resilience (Luthar \& Cicchetti, 2000). For example, someone may overcome adversity and show resilience by achieving considerable success in their academic grades but not show success in their peer relationships, or vice versa. It is not un-resilient to show success in one area and not show it in another unrelated domain. Naturally, there is an expected level of variation between success in different domains of one's life. Resilience does not require a positive outcome in every domain but rather a positive outcome where less positive outcomes are expected. This is the multidimensionality of resilience. Accordingly, resilience research needs to be specific about the outcome domain resilience is being tied to, choosing outcome measures that are related to the area of adversity . Moreover, it is important to understand the way in which a 'good' outcome is conceptualised, paying attention to cultural, religious and personal variations in what is positive or successful, as well as considering that some outcomes may be positive or adaptive given their context (Hopkins et al., 2018). 
SOCIAL FUNCTIONING \& RESLIENCE IN YOUNG PEOPLE

Resilience is of interest because greater resilience levels are linked to less negative mental health and social outcomes across each individual's lifetime, and because resilience helps individuals overcome adversity or stress (Khanlou \& Wray, 2014; Hjemdal et al., 2006; Hjemdal et al., 2011; Anyan \& Hjemdal, 2016; Klibert et al., 2014). Additionally, a review of the literature suggests that resilience focused interventions lead to improved mental health outcomes for both children and adolescents, although the effect varies according to psychopathology and is different across these two age groups (Dray et al., 2017). This will be discussed further in section 1.8 .

Overall, it is important to understand that resilience research is a complicated field with large variations in how it is conceptualised (Liu et al., 2017; Vella \& Nagesh, 2019). This leads to a range of measures based on different conceptualisations. Liu et al. (2017) suggest paying attention to resilience processes at the individual, interpersonal and socioecological levels. Accordingly, the current study has conceptualised resilience in this way, as a dynamic process, with mechanisms occurring at multiple levels in an individual's life. In the context of a cross-sectional study, resilience can still be considered as dynamic by investigating factors which are related to greater resilience. Future research can further investigate whether these factors are able to lead to or cause greater resilience.

\subsection{Social functioning}

Social functioning is a broad term for a range of abilities and behaviours which occur in a social setting or influence social behaviour, for example in a school or work setting, or in the home with other family members (Dodge \& Pettit, 2003; Bijstra et al., 1994, Haas et al., 2018). Social functioning includes the ability to sustain and the quality of friendships and relationships, how someone works with peers, their ability to participate in prosocial behaviours or recognise and empathise with other people. Moreover, greater social skills and relationships are linked to greater well-being or more life positive outcomes (Segrin \& 
Taylor, 2007; Segrin \& Rynes, 2009; Nilsen et al., 2013; Bijstra et al., 1994; Gartland et al., 2019). This is theorised to be in part because individuals with greater social skills can access greater social support which in turn can protect them against psychological distress or difficulties (Segrin et al., 2016). This in itself, is a form of resilience occurring.

Engels et al. (2001) completed structural equation modelling which showed that for 1518 year olds, parental attachment was related to social skills and social anxiety which in turn were related to feelings of relational competence and, in turn again to self-esteem. However, this effect was not found in younger adolescents. Engels et al.'s findings suggest that the environment young people experience (i.e. attachment models and parenting relationships) can influence social functioning, which in turn can help influence positive outcomes.

Similarly, Segrin and Taylor (2007) showed that in adults, positive relationships with other people mediated the relationship between social skills and multiple indicators of wellbeing (life satisfaction, environmental mastery, self-efficacy, hope, happiness, quality of life). This further emphasises the idea that positive social functioning contributes to positive outcomes.

\section{Empathy}

Empathy is the ability to understand, and or respond to the state, especially emotional state, of another person (Waller et al., 2020). This falls within social functioning as it requires someone to recognise another person's mental or emotional state and then have an emotional reaction to them. Affective empathy involves recognising and feeling the emotional state of another person whereas cognitive empathy removes this emotional response (Waller et al., 2020). In this way, affective empathy requires more social functioning and cognitive empathy requires less. The current study focuses on the affective aspects of empathy which implicate a social environment, i.e., perspective taking and empathic concern, instead of focusing on aspects of empathy which are self-oriented, i.e. personal distress and fantasy (connection to 
fictious characters and worlds). Vinayak and Judge (2018) showed that in adolescents aged 13-15, both empathy and resilience were correlated with greater psychological well-being. However, this study excluded participants where either themselves or their parents had mental and/or physical health conditions. This may have potentially skewed the results to be only be applicable in a lower risk sample of adolescents. Still, this study suggests it is worth further considering the role empathy may play, within the context of social functioning, in increasing positive outcomes. Similarly, Silke et al. (2018) found in their systematic review that empathy and prosocial behaviour were significantly related suggesting that the more empathic someone was, the more likely they were to engage in helpful or prosocial behaviours. This might suggest that empathy has a role to play in increasing the quality of someone's social functioning which, in turn, is hypothesised to increase resilience.

\section{Prosocial behaviour}

Prosocial behaviour refers to the proactive and reactive behaviours that individuals engage in to support others and enhance their well-being (Waller et al., 2020). Like empathy, prosocial behaviour is associated with a range of individual and contextual factors which means that these behaviours can be encouraged through the environment (Silke et al., 2018). Nantel-Vivier et al. (2014) found that whilst prosocial behaviour was associated with less aggression in children, prosocial behaviour did not have an obvious relationship to internalising behaviours. Indeed, they found an association between being part of the low prosocial behaviour category and being part of either the extremely low or the high depression category but not the low or moderate categories. This suggests that whilst prosocial behaviour is linked to positive behavioural outcomes, it is not necessarily related to increased well-being on a broader level.

\section{Peer difficulties/peer relationships}


Peer relationships pertain to the nature and quality of the relationships a young person has with those around them of a similar age. This is part of social functioning as being able to attain and maintain these relationships requires social skills. Accordingly, having and maintaining friendships as well as the quality of these friendships also might be considered part of peer relationships. Van Harmelen et al. (2017) found that for adolescents, higher levels of friendship and friend support is linked to greater resilience in the presence and across time. Van Harmelen et al. (2016) showed that among adolescents who had experienced early life stress, friendships in adolescence mediated the pathway between peer bullying and depressive symptoms. Criss et al. (2002) found similar results with children where peer acceptance moderated the link between family adversity and externalising behaviours. This suggests that better peer relationships are linked to more positive outcomes and may protect against negative outcomes.

\section{Collaboration}

Collaboration, the action of working with others, falls under the breadth of social functioning. This skill and behaviour involves working alongside another or multiple other people, understanding that person's value and ability to contribute to any given task. There is not much research showing how collaboration might lead to better social or life outcomes. However, Strough et al. (2001) found that for young adolescents, having greater expectations that they would enjoy a task prior to being assigned a partner to work with, was related to greater expectations of enjoying that task after partners were assigned. Having greater expectations that one would enjoy a task as well as greater perceived affiliation, agreement or influence with their partner, were all related to better performance on a task. This research suggests that friendship and attitudes or expectations about collaborating on a task might both play a role in young adolescents effectively completing a task. However, the research does not go further and say whether collaboration might in turn lead to greater friendship or strong 
SOCIAL FUNCTIONING \& RESLIENCE IN YOUNG PEOPLE

peer relationships. Despite this, collaboration is another way in which individuals must form connections and communicate with peers and so falls within the umbrella of social functioning.

\subsection{Resilience and Social Functioning}

Resilience's biopsychosocial nature implicates social functioning. Indeed, families are widely considered as an essential resource for childhood resilience (Cicchetti, 2013) and similarly, as young people expand their social networks to include friends, these friendships and relationships can become a source for positive or negative influence. Being able to understand others' perspectives, collaborate, display prosocial behaviour or form relations with peers are all skills that might greaten the resilience one can draw on from others. Additionally, it is possible that resilience has a similar reciprocal effect, where greater resilience allows for more or higher quality social functioning (Hopkins et al., 2014).

For example, higher rates of peer acceptance and friendship attenuate the relationship between family adversity and externalising behaviours in children (Criss et al., 2002). This suggests that peer acceptance and friendship offer some protection against developing externalising behaviours (such as conduct problems) when faced with family adversity. Similar research showed that for healthy teenagers, increased friendship and family support was linked to greater resilience concurrently but that this relationship only held across time for friendship support (van Harmelen et al., 2017). Social support functioned as a buffer against the effects social exclusion has on adolescent's wellbeing (Arslan, 2018). Segrin et al. (2007) showed that for university students, the positive relationship between social skills and well-being (as measured by life satisfaction and reduced symptoms of depression) was mediated by perceptions of stress. This suggests that social functioning impacts positive life outcomes but is also affected by an individual's experience of stress or difficulty. 
This emphasises the importance of peer relationships, especially in adolescence, as young people become increasingly independent and form their own support networks (Smetana et al., 2006).

Moreover, psychopathy, a construct akin to callousness for adults, was protected against by peer relationships and the quality of romantic relationships for youth who were offending in a severe manner (Backman et al., 2018). Both peer and romantic relationships were protective against each of the subdomains of the psychopathy scale employed; CU traits, grandiose manipulative traits and impulsive irresponsible traits. This study further highlighted that the quality of the romantic relationship is an important consideration because romantic partners can either exert an antisocial or a prosocial influence.

The above research suggests that resilience may protect individuals with callousunemotional $(\mathrm{CU})$ traits and conduct problems (CP) from developing worse social functioning. Moreover, the above research also suggests that social functioning may protect individuals with $\mathrm{CU}$ and $\mathrm{CP}$ from developing other similar harmful traits or worse outcomes.

\subsection{Conduct Problems}

Conduct problems (CP), closely related to the DSM-IV's Conduct Disorder, are a repetitive and persistent pattern of clinically significant violations of social norms or the rights of others (American Psychiatric Association; APA, 2013; Fairchild et al., 2019). This involves acts of aggression, violence, dishonesty, defiance, bullying, damaging property or disregarding rules and instructions. $\mathrm{CP}$ is a broad label which includes the formal diagnosis of conduct disorder but also includes a wider range of undiagnosed, unrecognised, subclinical or related conduct problems. Individuals with $\mathrm{CP}$ present at a greater risk for worse psychosocial outcomes such as crime, substance use or mental health issues even when controlling for potential confounding factors in ones' life (Fergusson et al., 2005; Hammerton et al., 2019). The nature of CP itself, alongside the negative trajectories and the adverse life 
outcomes seen in $\mathrm{CP}$ emphasise the importance of understanding and intervening on these behaviors early.

The DSM's diagnosis of Oppositional Defiant Disorder (ODD) also falls within the broad category of $\mathrm{CP}$ with individuals displaying patterns of irritable or angry moods and argumentative or defiant behaviours. Whilst ODD is its own distinctive diagnosis, ODD does predict CP in later years (Rowe et al, 2002; Rowe et al., 2010; van Lier et al., 2007).

Additionally, attention deficit hyperactivity disorder (ADHD) also sometimes falls within the broad category of CP. Whilst ADHD does not necessitate the rule breaking, oppositional or antisocial behaviour typical of $\mathrm{CP}$, ADHD does present as a potential risk factor for later $\mathrm{CP}$; although this pathway risk is to a lesser extent than it is for ODD (van Lier et al., 2007; Loeber \& Burke et al., 2011; Dick et al., 2005). Indeed, youth with both conduct disorder and ADHD are more likely to be arrested at an earlier age and have more arrests than those with either diagnosis alone (Forehand et al., 1991). This suggests that whilst ADHD may not play a major role in the development of $\mathrm{CP}$ as previously thought, the comorbid presence of ADHD may be a risk for worse symptoms and worse outcomes (Deault, 2010). In this way, CP represents a broader array of difficulties than a conduct disorder diagnosis can account for.

Despite this, one way research is often done is through use of a clinical sample where all participants have a conduct disorder diagnosis. Clinical samples provide information regarding more severe cases of $\mathrm{CP}$ and screens out individuals with confounding comorbidities easier. However, using a clinical sample may overlook individuals with subclinical symptoms or those who do meet criteria but do not receive a diagnosis (either due to clinical judgement or being attended to by a non-diagnostic service). Moreover, recruiting a clinical population can be impractical and time-consuming. 
SOCIAL FUNCTIONING \& RESLIENCE IN YOUNG PEOPLE

An alternative way to conduct research is to measure $\mathrm{CP}$ with broadband psychometric tools such as the Strengths and Difficulties Questionnaire (SDQ; Goodman et al., 1998). Measuring via a broadband or psychometric allows for greater sample sizes and easier recruitment. This method can also provide a continuous scale of $\mathrm{CP}$ levels meaning richer questions about how CP might change in severity or overtime can be asked. Norms can also be used to convert this scale into categorical data (i.e. high $\mathrm{CP}$ and low $\mathrm{CP}$ ).

\subsection{Callous-Unemotional Traits}

Callous-unemotional (CU) traits are traits or behaviours displaying limited empathy or guilt, shallow affect or a poverty of emotions (Wall et al., 2016; Viding \& McCrory, 2012). Considered the child and adolescent precursor to the adult construct of psychopathy, these traits predict greater behavioural issues and greater resistance to treatment (Frick et al., 2014b). By definition, CU traits implicate difficulties in how individuals function socially. However, the presence of $\mathrm{CU}$ traits is also accompanied by other patterns of difference in the genetic, biological, and cognitive domains (Frick et al., 2014b; Saunders et al., 2019;

Takahashi et al., 2020). For example, a cognitive difference seen in CU is reduced emotional responsiveness to situations.

Due to the DSM's current structure, CU traits are most often considered within the context of $\mathrm{CP}$ as $\mathrm{CU}$ is an additional specifier to a conduct disorder diagnosis (American Psychiatric Association, 2013). Despite this, CU traits do not necessitate CP. In fact, a growing body of research has been investigating what $\mathrm{CU}$ without any $\mathrm{CP}$ looks like. For example, individuals high on CU (but without $\mathrm{CP}$ ) have fewer difficulties with hyperactivity/impulsivity, fewer executive functioning deficits, higher self-regulation and these individual's parents report more positive parenting than for individuals who have high levels of both CU and CP (Wall et al., 2016). This indicates that CU cannot just be 
considered a subset of $\mathrm{CP}$ but instead the two need to be looked at in combination with one another.

CU's role as a specifier for CP in the DSM means that CU traits are often used to help explain the heterogeneity of $\mathrm{CP}$ populations. Children exhibiting both $\mathrm{CP}$ and $\mathrm{CU}$ display a more severe and chronic pattern of antisocial or risky behaviour over subsequent years (Frick et al., 2005; Frick et al., 2014a; Robertson et al., 2020; Thornton et al., 2019; Pardini \& Fite, 2010). This includes acts of aggression, substance use and risk taking within sexual behaviour. One study showed that children aged 3 with CU, later show higher levels of proactive, reactive and relational aggression aged 10 although this was additionally moderated by executive functioning (Waller et al., 2017). Another study showed that children with low fear who have experienced harsher parenting are more likely to display CU traits and engage less socially with researchers in a lab experiment (Waller et al., 2019). Moreover, young people expressing both $\mathrm{CU}$ and $\mathrm{CP}$ show poorer outcomes after standard $\mathrm{CP}$ treatment than can be explained by just having greater levels of CP to begin with (Hawes et al., 2014). Accordingly, where $\mathrm{CU}$ is present, any treatment for $\mathrm{CP}$ might need to be adjusted such as a greater emphasis on social skills training where intervention might otherwise focus on working with parents (Wilkinson et al., 2016).

The heterogeneity of CP expression has driven more research into the CU field meaning there is an array of ways CU is currently measured. One common tool is the Inventory of Callous Unemotional Traits (ICU; Frick, 2003; Ray \& Frick, 2020). This measure was designed to capture the affective nature of $\mathrm{CU}$ whereas psychopathy scales regard callousness as only one dimension. The ICU creates a sum score for level of CU based on self-report, parent or teacher ratings. 


\subsection{Subtypes of Callous Unemotional Traits and Conduct Problems}

Evidentially, it is not possible to thoroughly understand either $\mathrm{CU}$ or $\mathrm{CP}$ in isolation from the other; regarding the two as a homogenous group can lead to effects being cancelled out (Frick et al., 2014a; Frick et al., 2014b). Whilst it is possible to express only CU or only $\mathrm{CP}$ without the other, the combination of both presents unique difficulties in management, treatment and life outcomes. For this reason, it is important to consider the co-occurrence and/or the relationship between $\mathrm{CP}$ and $\mathrm{CU}$ in research. One way to do this is to break $\mathrm{CU}$ and $\mathrm{CP}$ down into categories.

One approach considers the chronicity and stability of such traits by measuring onset time and persistence of CP. Individuals are classed into four groups; early onset persistent (EOP), childhood limited (CL), adolescent limited (AL) and adolescent onset (AO) (Frick \& White, 2008; Frick et al., 2014b; Bevilacqua et al., 2018; Gutman et al., 2019). This allows for a richer understanding of how expressing $\mathrm{CP}$ continuously or discontinuously at different stages of life can predict different outcomes. For example, it is theorised that the poorer outcomes seen in individuals with EOP CP (early onset persistent conduct problems) are due to experiencing cumulative consequences or snares which limited prosocial pathways or chances to learn prosocial behaviours (Bevilacqua et al., 2018). This group displays more

\section{Figure 1}

Intersection of CU Traits and CP to Form Groups.

\section{Callous Unemotional Traits (CU)}

\begin{tabular}{cc|c|c} 
& & High levels & Low levels \\
\cline { 2 - 3 } $\begin{array}{c}\text { Conduct } \\
\text { Problems (CP) }\end{array}$ & High levels & HCU HCP & LCU HCP \\
\cline { 2 - 4 } & Low levels & HCU LCP & LCU LCP
\end{tabular}


aggression overall and is more likely to carry antisocial behaviour into adulthood criminality (Frick \& Kemp, 2020).

Individuals with EOP CP are considered to be most at risk of poorer outcomes whereas those with CL CP tended to be low risk (Bevilacqua et al., 2018). This implies that longitudinal research should also consider how the onset times of CP may influence long term outcomes or severity.

An alternative approach for differentiating $\mathrm{CU}$ and $\mathrm{CP}$ is to separate samples into subgroups where each trait is seen as high or low based on current presentation. Whilst this often would involve four groups (as seen in Figure 1), sometimes six groups are identified by latent profile analyses adding groups that include traits between high and low or if individuals are increasing in a trait (Fanti et al., 2013; Eisenbarth et al., 2016; Wall et al., 2016; Klingzell et al., 2016, Fanti et al., 2015). Categorising individuals this way allows for both $\mathrm{CP}$ and $\mathrm{CU}$ to be seen in isolation (high on one trait and low on the other) and combined (high on both traits) whilst providing a control group (low on both traits). This approach provides no information about the order in which difficulties emerged in the individual's life or about the chronicity of these difficulties. However, this categorical approach to whether CU or CP traits are present allows for easier comparisons to be made between groups. Additionally, this approach may be expanded to contain a fifth subgroup of those who are increasing in $\mathrm{CU}$ and $\mathrm{CP}$ traits although, again, longitudinal data is needed to make this adjustment (Eisenbarth et al., 2016).

When looked at through this categorical approach, individuals who are high on both $\mathrm{CU}$ and $\mathrm{CP}\left(\mathrm{H}_{\mathrm{CU}} \mathrm{H}_{\mathrm{CP}}\right)$ are at a greater risk of worse long-term outcomes (Fontaine et al., 2011). The $\mathrm{H}_{\mathrm{CU}} \mathrm{H}_{\mathrm{CP}}$ group score higher than other groups on levels of proactive aggression, narcissism, exposure to media violence and experiences of peer pressure but score lower on self-esteem measures (Eisenbarth et al., 2016). One theory regarding their low self-esteem 


\section{SOCIAL FUNCTIONING \& RESLIENCE IN YOUNG PEOPLE}

postulates a heightened vulnerability and striving for peer conformity and popularity. These individuals also show lower fear startle potentiation, low behavioural inhibition and are less sensitive to punishment than those high on CP but low on CU (Fanti et al., 2015). This further indicates heterogeneity in the $\mathrm{CP}$ population and how they experience emotions in relation to their environments.

Individuals who are high on $\mathrm{CU}$ but low on $\mathrm{CP}\left(\mathrm{H}_{\mathrm{CU}} \mathrm{L}_{\mathrm{CP}}\right)$ tend to score lower on anxiety and reactive aggression (Eisenbarth et al., 2016). This might indicate that stronger emotion and behaviour regulation abilities protect these individuals from engaging in antisocial behaviour. This group also tends to have lower levels of impulsivity than the $\mathrm{H}_{\mathrm{CU}}$ HCP group and report being more connected to their school (Wall et al., 2016). Parents of those with $\mathrm{H}_{\mathrm{CU}} \mathrm{L}_{\mathrm{CP}}$ also report that their children were more involved and more positive than those who are high on both.

Individuals who are low on $\mathrm{CU}$ but high on $\mathrm{CP}\left(\mathrm{L}_{\mathrm{CU}} \mathrm{H}_{\mathrm{CP}}\right)$ showed lower proactive aggression than the HCU HCP group but equal reactive aggression (Eisenbarth et al., 2016). This LCU $\mathrm{H}_{\mathrm{CP}}$ group also had higher self-esteem than the high on both group and lower media exposure to violence. This indicates that whilst both groups display similar levels of $\mathrm{CP}$, how individuals varying on $\mathrm{CU}$ and $\mathrm{CP}$ experience the social world is different.

This variation also indicates that by classing CU and CP into four separate groups, richer information is found about individuals who may initially present with similar behavioural problems. Interestingly, there is an asymmetry in the association between $\mathrm{CU}$ and CP. Children with high levels of CU are very likely to also present with high levels of CP but children with high levels of $\mathrm{CP}$ are only moderately likely to also present with high levels of CU (Fontaine et al., 2011). This is consistent with the asymmetry between CU and CP's adult correlates; psychopathy and antisocial behaviour. This also further augments the need to 
SOCIAL FUNCTIONING \& RESLIENCE IN YOUNG PEOPLE

see CU and CP in relation to one another as they exert differential effects on the other and produce different outcomes.

\subsection{Social Functioning in Callous-Unemotional Traits and Conduct problems}

The nature of both $\mathrm{CU}$ and $\mathrm{CP}$ requires considering social functioning. Not only does the increased antisocial behaviour of both $\mathrm{CU}$ and $\mathrm{CP}$ implicate aggression against others, but CU and CP both present with layers of emotional, cognitive and behavioural deficits which in turn can produce changes in social functioning. For example, individuals who exhibit $\mathrm{CP}$ persistently from early childhood have reduced opportunities to learn prosocial behaviours from peers. This means that across their lifetime, these individuals develop less alternatives to the antisocial behaviour they are exhibiting. This restricted repertoire, a type of cumulative consequence, means individuals are less equipped to respond positively to situations they are confronted with.

The role of social functioning is further pertinent in adolescence where increases in independence lead to friends and peers becoming a greater source of social support (Smetana et al., 2006). These relationships not only provide support but provide opportunities to learn or refine social skills. Moreover, a desire to maintain friendships, and the support which accompanies that, might motivate individuals to develop or employ social skills such as empathy or collaboration where previously there was no motivation. However, some individuals who have displayed persistent difficulties throughout childhood may not have the required skills to build friendships in adolescence having missed the opportunities to learn these skills earlier on. Additionally, whilst friendships provide a chance and the motivation to learn prosocial behaviours and skills, by this same logic, they provide the opportunity to learn antisocial behaviours (Smetana et al., 2006; Backman et al., 2018).

Within the context of CU traits and CP, a longitudinal study showed that higher levels of CU predicted lower friendship quality 6 months later and that similarly, lower friendship 


\section{SOCIAL FUNCTIONING \& RESLIENCE IN YOUNG PEOPLE}

quality was predictive of greater CU at a 6-month delay (Miron et al., 2020). This held constant even whilst controlling for impulsivity, manipulative behaviours and aggression. Other longitudinal research additionally shows that high CU traits at age 3 predict greater dislike by peers age 10 (Waller et al., 2017). Children with high CU also show greater loneliness and lower friendship satisfaction and social competence even after controlling for both CP and ADHD (Haas et al., 2018). Fanti et al. (2017) corroborate these social competence findings and additionally show that children with high CU show lower levels of self-regulation, empathy, school connectedness and peer support. Among other measures, positive behaviour support in children 2-3 years old was associated with lower levels of caregiver reported $\mathrm{CP}$ age 5 suggesting that learning prosocial and positive behaviour may protect against CP (Vanderbilt-Adriance et al., 2016).

Additional research shows that ODD is associated with increased peer problems in 612 year olds (Andrade et al., 2015; APA, 2013). However, this study also showed that CU did not have any moderating effect on this relationship. Interestingly, the same study found that CU traits moderated the significant relationship between impulsivity/overactivity and peer problems further indicating a complex relationship between $\mathrm{CU}, \mathrm{CP}$ and indicators of social functioning.

In young teenagers, both $\mathrm{CU}$ and $\mathrm{CP}$ were separately correlated with higher levels of peer relationship issues and lower levels of prosocial behaviour, although this relationship was stronger for CU (Viding et al., 2009). In late childhood, higher levels of CU were stronger predictors of physical victimisation in early adolescence than any of $\mathrm{CP}$, emotional problems, family socioeconomic status or negative parental discipline (Fontaine et al., 2018). The same research showed that youth with increasing, decreasing or stable high levels of CU showed greater levels of all forms of peer victimisation than those low in CU. Another study found that a childhood measure of psychopathy predicted peer rejection above and beyond 
other known diagnostic and behavioural risk-factors (i.e. ADHD) but was unrelated to peer popularity (Piatigorsky \& Hinshaw, 2004). Interestingly, in a community sample of adults Egan and Bull (2020) found that increased risk taking and offending was correlated with increased psychopathy levels but that this was not moderated by social support from peers. This might be because peers can have an influence towards positive behaviours (i.e. prosociality) or towards negative behaviours (i.e. antisociality) and so the nature of social support needs to be taken into consideration.

Moreover, social functioning not only is an area of difficulty for those with CU and CP but it also provides an area of intervention, especially when interventions with parents are not viable or have been exhausted (Wilkinson et al., 2016). Behavioural interventions for CP have been adapted for individuals also expressing CU to focus more on rewards and less on punishments (Waschbusch et al., 2019). Most commonly, the interventions for CP used with adolescents after parental training has been tried involve Multisystemic Therapy or similar high intensity interventions that work at home, at school and in all other domains of an individual's life (Fairchild et al., 2019). These interventions aim to increase an individual's association with prosocial peers and their problem solving skills as well as improve their social and emotion regulation, their access to greater support around them (at school, home or in the community) and their school achievement. In this way, these evidence based approaches have a broader view of treatment that includes the individual's social functioning and access to support.

\subsection{Resilience, Conduct Problems and Callous-Unemotional traits}

As previously discussed, resilience is the process of achieving positive outcomes in the presence of difficulties. Not only are $\mathrm{CU}$ and $\mathrm{CP}$ examples of such difficulties which one may overcome, but the preceding risk factors and associated outcomes of $\mathrm{CU}$ and $\mathrm{CP}$ are also difficulties to overcome. Indeed, one New Zealand study showed that for young people, the 


\section{SOCIAL FUNCTIONING \& RESLIENCE IN YOUNG PEOPLE}

factors most effecting resilience levels were gender, conduct problems, depression and parental monitoring (Boden et al., 2018). This study also suggested that the same factors are predictive of resilience across individuals with differing levels of adversity. However, an Australian study showed that risk and resilience factors work differently for Aboriginal youth of high and low risk contexts (Hopkins et al., 2014). Notably, in high family risk environments, having a prosocial friend had a positive impact on a young person's psychosocial functioning. This effect was not found for the lower risk group which suggests that predictors of resilience are not consistent across all populations. This, in turn, suggests a need to study resilience across groups with different risk profiles to understand how resilience may be uniquely operating in that profile. In the context of the current study, individuals with either $\mathrm{CU}$ or $\mathrm{CP}$, or both, present with differing risk profiles for different outcomes. This may mean that for individuals who are high on both or only one of CU and $\mathrm{CP}$, there may be different patterns in how resilience develops.

Indeed, research in this area has suggested that resilience may attenuate the relationship between callousness and aggression (Kauten et al., 2013). Considering the effect callousness has on aggression (as part of the scope of social functioning), the attenuating role of resilience suggests that it could play a role in achieving better social outcomes in the presence of risk. Moreover, aspects such as parental-social support and neighbourhood quality, both features of an ecological approach to resilience, are associated with low levels of primary caregiver reported CP in early childhood (Vanderbilt-Adriance et al., 2016) Moreover, resilience focused interventions might reduce some mental health outcomes in children and youth although these effects varied by specific psychopathology, age, gender and follow-up length (Dray et al., 2017).

Resilience is a construct of focus in the current study due to the documented role it plays in overcoming adversity (whether through ameliorating an intervention or via other 
SOCIAL FUNCTIONING \& RESLIENCE IN YOUNG PEOPLE

pathways). As part of this, understanding covariates of improved resilience may provide avenues for future study regarding how to actively promote resilience. In the current study, the possible covariate in question is social functioning. Furthermore, the connection between greater social functioning and greater resilience in a normal, typically developing population should not be assumed to still be true for a population representing greater adversity. This means it is important to not only understand whether social functioning offers an inlet for encouraging greater resilience but also whether this inlet holds up in the presence of greater difficulties.

\subsection{The Current Study}

The current study aims to investigate the relationship between social functioning and resilience whereby social functioning includes measures of collaboration, empathic concern, perspective taking (empathy), peer relationships and prosocial behaviour. This multiple regression will be run four times across the groups of high and low $\mathrm{CU}$ and $\mathrm{CP}$.

It is expected that greater levels of social functioning will be correlated with greater levels of resilience. This is particularly expected to occur for prosocial behaviour and peer relationships due to these constructs reflecting the social support aspect that resilience encapsulates.

It is also expected for the individuals who have high levels of both $\mathrm{CU}$ traits and $\mathrm{CP}$, the relationship between social functioning and resilience will be weaker. This may be because the adversity that tends to be experienced more for individuals with high levels of $\mathrm{CU}$ and $\mathrm{CP}$, may act to block greater resilience from occurring. For example, the weaker social connections seen for individuals with high levels of conduct problems may prevent individuals from accessing social support. 


\section{Chapter 2. Method}

\subsection{Participants}

In total, 924 students aged 11-15 received invitations to participate in an online survey that formed part of a wider intervention-based study in their high school. From these invites, 431 students completed the survey. From this, participants were removed who had missing data, missing ID numbers or unreliable responding patterns leaving 381 participants. Participants were then removed who completion time was more than 3 standard deviations away from the mean $(M=39.63, S D=6.89)$. A test of homoscedasticity for multiple regressions revealed four outliers in the $\mathrm{L}_{\mathrm{CU}} \mathrm{L}_{\mathrm{CP}}$ group which were then removed in order to meet assumptions for a multiple regression. The final data set was comprised of 374 (females $=191$, gender not specified $=2$ ). The data set had 64 participants from year 7, 170 participants from year 8, 139 participants from year 9, and 1 participant with an unspecified year level.

\subsection{Measures}

Callous Unemotional Traits. Callous-Unemotional traits (CU) were measured by the Inventory of Callous-unemotional traits (ICU) youth version (Frick, 2003). The ICU is a 24 item 4-point Likert scale where participants respond from 0 (not true at all) to 3 (definitely true). The scale includes three subscales; callousness (e.g., "the feelings of others are unimportant to me”), uncaring (e.g., "I care about how well I do at school or work") and unemotional (e.g., "I hide my feelings from others"). The full score was used in the current study and not these subscales. In the current sample, Cronbach's alpha was .83.

Conduct Problems. Conduct Problems (CP) were measured via the 5-item conduct disorder subscale of the self-report Strengths and Difficulties Questionnaire (SDQ; Goodman et al., 1998). Participants rate the extent to which a statement (e.g., "I get very angry and 
often lose my temper") is true of them on a 3-point Likert scale from 0 (not true) to 2 (certainly true). In the current sample, Cronbach's alpha was .61.

Peer Relationships. Peer relationships were measured via the 5-item peer difficulties subscale of the SDQ (Goodman et al., 1998). Participants rated on a 3-point Likert scale from 0 (not true) to 2 (certainly true) the extent to which they agreed with statements such as "I get on better with adults than with people my own age". Higher scores on this scale are associated with greater difficulties. For the purpose of this study and its analyses, this scale was reverse coded to be a positive construct titled 'Peer Relationships (-)' to reflect the recoding. In the current sample, Cronbach's alpha was .56.

Prosocial behaviour. Prosocial behaviour was measured via the 5-item prosocial behaviour subscale of the SDQ (Goodman et al., 1998). Participants rated on a 3-point Likert scale from 0 (not true) to 2 (certainly true) the extent to which they agreed with statements such as "I am helpful if someone is hurt, upset or feeling ill". In the current sample, Cronbach's alpha was .74.

Collaboration. Collaboration was measured via an adapted 21 item questionnaire originally designed for undergraduate university students (see Appendix A). This questionnaire investigates attitudes towards collaboration in school (e.g., "students learn a lot of important things from each other") and the sense of school community (e.g., "my teachers want me to do the best I can”). Participants responded on a 5-point Likert scale from 1 (almost never true) to 5 (almost always true). In the current study, Cronbach's alpha was .86.

Empathy. Empathy was measured using the 28 Item Interpersonal Reactivity Index (IRI; Davis, 1980; Davis, 1983). The IRI includes four 7 item subscales; perspective taking (e.g., "before criticising somebody, I try to imagine how I would feel if I were in their place"; $\alpha=.70$ ), empathic concern (e.g., "when I see someone being taken advantage of, I feel kind of protective towards them"; $\alpha=.78$ ), fantasy (e.g., "I really get involved with the feelings of the 
SOCIAL FUNCTIONING \& RESLIENCE IN YOUNG PEOPLE

characters in a novel"; $\alpha=.70)$ and personal distress (e.g., "I tend to lose control during emergencies"; $\alpha=.64)$. Items were rated on a 5-point Likert scale as not describing them well (1) and describing them very well (5). Only the perspective-taking and empathic concern subscales were used for the current study. The fantasy and personal distress subscales were excluded from the current study due to being les relevant to social functioning and instead reflecting more of a cognitive ability for empathy. In the current sample, Cronbach's alpha for the full empathy scale was .82 .

Resilience. Resilience was measured using the 12 item Child and Youth Resilience Measure - 12 (CYRM-12; Lyneham et al., 2008). This measure takes an ecological approach to resilience, considering the individual, their relationships and what resources can be accessed across their community. Participants were asked to respond to statements on a 5point Likert scale (e.g., "I try to finish what I start") by saying whether it describes them a lot (5) or not at all (1). Some words were adapted in the scale to increase understanding and relevancy to the school (see Appendix B). In the current sample, Cronbach's alpha was .84.

\subsection{CU and CP Groups}

Subgroups of CU and CP were built matching characteristics that are usually found in latent profile analysis of data where individuals are considered to have one, both or neither of CU and CP (Fanti et al., 2013). For the current study, participants were scored as being high (top $25 \%$ of the scale) or low (bottom $75 \%$ of the scale) for both $\mathrm{CU}$ and $\mathrm{CP}$ measures. From this, participants were allocated to one of the four groups which represented the four possible combinations of the two sets of scores; $\mathrm{H}_{\mathrm{CU}} \mathrm{H}_{\mathrm{CP}}(n=40), \mathrm{L}_{\mathrm{CU}} \mathrm{H}_{\mathrm{CP}}(n=34), \mathrm{H}_{\mathrm{CU}} \mathrm{L}_{\mathrm{CP}}(n=53)$ and $\mathrm{LCU}_{\mathrm{CU}} \mathrm{L}_{\mathrm{CP}}(n=246)$.

An ANOVA comparing the four groups for their level of CU traits (ICU) showed a significant difference $(F(3,370)=184.5, p<.001$. Post hoc Tukey HSD tests showed significant differences between all groups except between $\mathrm{H}_{\mathrm{CU}} \mathrm{H}_{\mathrm{CP}}$ and $\mathrm{H}_{\mathrm{CU}} \mathrm{L}_{\mathrm{CP}}$ (see Table 
1). As seen in Figure 2, this means that all groups had differing levels of CU aside from the two that were both classed as $\mathrm{H}_{\mathrm{CU}}$.

Comparing the four groups for CP (SDQ) showed a significant difference in level of CP between the 4 groups $(F(3,370)=203.1, p<.001$. Post hoc Tukey HSD tests revealed a significant difference between all groups except for $\mathrm{H}_{\mathrm{CU}} \mathrm{H}_{\mathrm{CP}}$ and $\mathrm{L}_{\mathrm{CU}} \mathrm{H}_{\mathrm{CP}}$ (see Table 1). As seen in Figure 2, this means that all groups had differing levels of $\mathrm{CP}$ aside from the two that were both classed as $\mathrm{H}_{\mathrm{CP}}$.

\section{Table 1}

Group Comparisons for $C U \& C P$

\begin{tabular}{|c|c|c|c|c|c|c|}
\hline \multirow[b]{2}{*}{ Variable } & \multicolumn{4}{|c|}{ Mean (standard deviation) } & \multirow{2}{*}{$p$} & \multirow{2}{*}{$\begin{array}{l}\text { Significant } \\
\text { differences } \\
\text { below }<.05\end{array}$} \\
\hline & $\begin{array}{c}\mathrm{LCU}_{\mathrm{CU}} \mathrm{L}_{\mathrm{CP}} \\
1 \\
\end{array}$ & $\begin{array}{c}\mathrm{H}_{\mathrm{CU}} \mathrm{L}_{\mathrm{CP}} \\
2 \\
\end{array}$ & $\begin{array}{c}\mathrm{LCU}_{\mathrm{CU}} \mathrm{H}_{\mathrm{CP}} \\
3 \\
\end{array}$ & $\begin{array}{c}\mathrm{H}_{\mathrm{CU}} \mathrm{H}_{\mathrm{CP}} \\
4 \\
\end{array}$ & & \\
\hline $\begin{array}{l}\text { Year } \\
\text { Level }\end{array}$ & $\begin{array}{c}8.20 \\
(0.73)\end{array}$ & $\begin{array}{l}8.25 \\
(0.63)\end{array}$ & $\begin{array}{l}8.35 \\
(0.69)\end{array}$ & $8.2(0.69)$ & .364 & \\
\hline Gender & $\begin{array}{c}0.47 \\
(0.50)\end{array}$ & $\begin{array}{c}0.60 \\
(0.50)\end{array}$ & $\begin{array}{c}0.58 \\
(0.50)\end{array}$ & $\begin{array}{c}0.63 \\
(0.49)\end{array}$ & .120 & \\
\hline $\begin{array}{l}\text { CU } \\
\text { Traits }\end{array}$ & $\begin{array}{l}21.71 \\
(6.02)\end{array}$ & $\begin{array}{l}36.90 \\
(4.84)\end{array}$ & $\begin{array}{l}26.04 \\
(5.82)\end{array}$ & $\begin{array}{l}39.60 \\
(4.81)\end{array}$ & $<.001 * *$ & $\begin{array}{c}2-1,3-1,4-1 \\
3-2,4-3\end{array}$ \\
\hline $\mathrm{CP}$ & $\begin{array}{c}1.87 \\
(1.32)\end{array}$ & $\begin{array}{c}2.74 \\
(1.15)\end{array}$ & $\begin{array}{c}5.74 \\
(1.05)\end{array}$ & $\begin{array}{c}6.15 \\
(1.08)\end{array}$ & $<.001 * *$ & $\begin{array}{c}2-1,3-1,4-1,4- \\
2,4-2\end{array}$ \\
\hline
\end{tabular}

Note. * indicates $p<.05 ., * *$ indicates $p<.01$. Gender was scored 0 for male and 1 for female, gender non-specified was excluded for this analysis. Year level had a range from year 7-9. Unspecified year level was also excluded from the current analysis. Year level and gender was tested with a chi square test. CU traits and $\mathrm{CP}$ were tested with an ANOVA.

\subsection{Procedure}

Participants from a high school in South England were invited to participate in an online survey. The survey contributed to the assessment and implementation of a school-wide 


\section{Figure 2}

Group Comparisons for CU and CP Levels

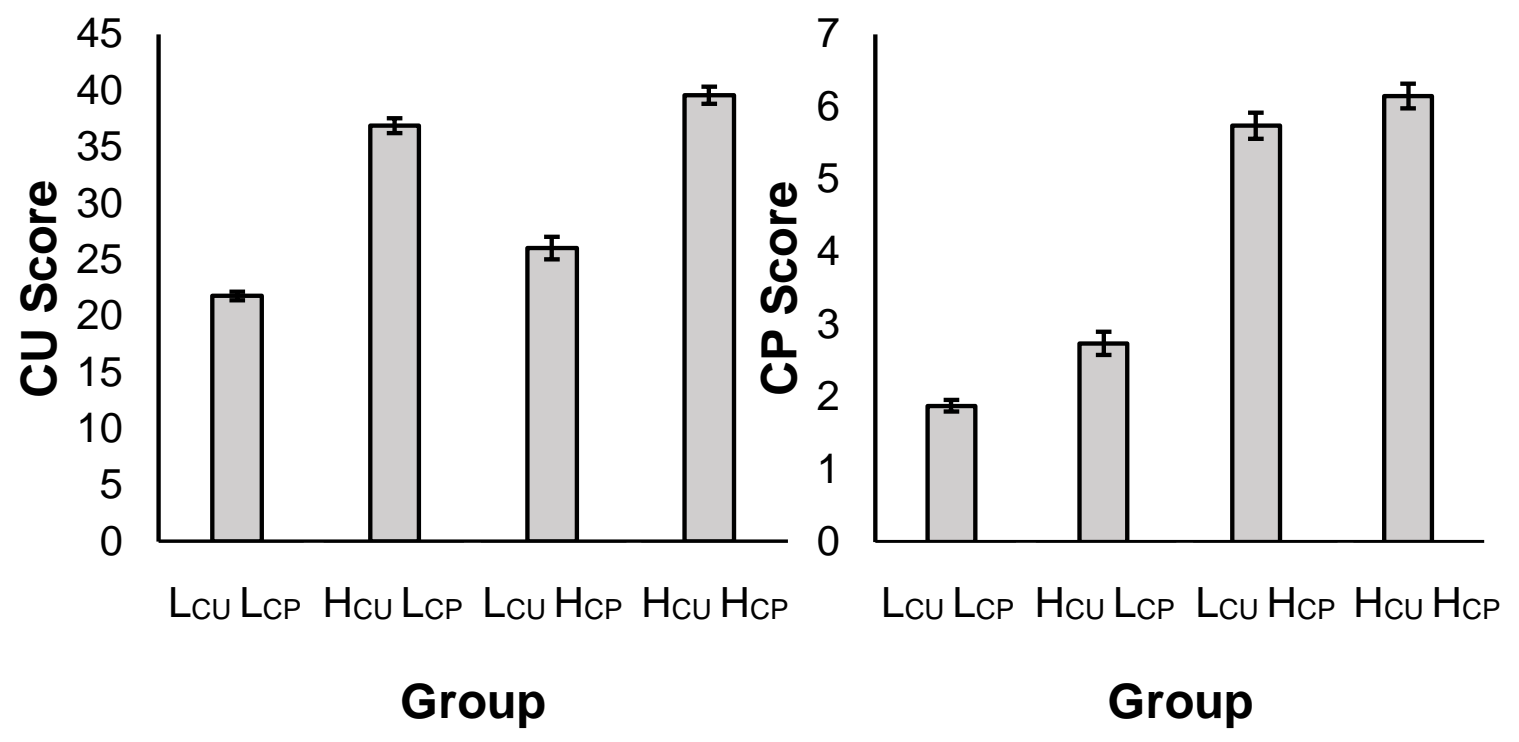

Note. $\mathrm{L}_{\mathrm{CU}} \mathrm{L} \mathrm{CP}=$ Low CU traits \& Low CP, $\mathrm{H}_{\mathrm{CU}} \mathrm{L}_{\mathrm{CP}}=$ High $\mathrm{CU}$ traits \& Low $\mathrm{CP}, \mathrm{LCU}_{\mathrm{CP}}=\mathrm{Low} \mathrm{CU}$ traits \& High $\mathrm{CP}, \mathrm{H}_{\mathrm{CU}} \mathrm{H}_{\mathrm{CP}}=$ High $\mathrm{CU}$ traits \& High CP.

school-based intervention that aimed to develop core skills to promote better learning. The school developed this intervention, and the University of Southampton was asked to monitor and evaluate its delivery. The head teacher consented to the research occurring at the school and organised parental consent through providing and information sheet and an opt-out form (see Appendix C).

Teachers read standardised instructions outlining the survey (see Appendix D). Students then read a preamble to the study (see Appendix E) before completing an online consent form (see Appendix F) and providing demographic information. Following this, they were invited to participate in the survey which was comprised of two blocks presented in the same order for everyone. Measures within the blocks were randomised. Block one included measures of resilience, curiosity, avoidance of novelty, metacognition, academic efficacy and self-management. At the end of this block, participants completed a creativity exercise where 
they were asked to generate as many alternate uses for everyday objects as they could. Following this, participants were offered an optional break before beginning block two. Block two included measures of collaboration, empathy, callous unemotional traits, worries in school and the SDQ. Block two was followed by a positive mood enhancer where participates were given two jokes and asked to rate them on a scale from 1 (not very funny) to 5 (very funny). Students were then provided with a debrief form (see Appendix G).

Other data collected as part of the wider study but not used here is reported elsewhere.

\subsection{Ethics}

The Ethics Committee of the Department of Psychology from the University of Southampton granted ethical approval for the current project (see Appendix H). Four main concerns were accounted for in the design of the study.

The first concern was that participants may become distressed, anxious or upset as part of the study. In response, teaching staff were present while the survey was completed, and the school counsellor was available for participants to speak to if wanted. It was also emphasised that participants could withdraw from the study at any point without any consequences.

The second concern was that participants may become restless or bored throughout the study. In response, a creativity task was included as a brief break between part 1 and part 2 of the study. A light-hearted joke rating task was also included at the end of the study.

A third concern was that there may be an increased risk of medical conditions or events (i.e. seizures) due to prolonged screen time. In response, teachers or other staff were present while the survey was completed. Parents or other guardians had been informed in advance of the survey and its length and it was highlighted that participants would need to look at a computer screen for an extended period. It was recommended that participants at risk of medical conditions and events being induced by prolonged computer use be withdrawn from the study prior to data collection. 
A fourth concern was that teachers may be at risk if students become distressed and aggressive as part of the study. The school already had protocols in place for any negative behaviours or incidents of this nature and the teachers present while the study was completed were familiar with their students. No further action was deemed necessary in response to this concern.

\subsection{Analysis Approach}

The current study tests multiple-regression models investigating the relationship between resilience (CYRM) and the social functioning variables of perspective taking (IRI), collaboration, peer relationships (-) (SDQ - reverse coded from peer difficulties), and prosocial behaviour (SDQ) (see Figure 3). As assumptions for a Linear Mixed Model including group as a factor were not met, multiple regression models were tested individually for each of the different CU \& CP groups separately $\left(\mathrm{H}_{\mathrm{CU}} \mathrm{H}_{\mathrm{CP}}, \mathrm{L}_{\mathrm{CU}} \mathrm{H}_{\mathrm{CP}}, \mathrm{H}_{\mathrm{CU}} \mathrm{L}_{\mathrm{CP}}\right.$, and $\mathrm{L}_{\mathrm{CU}}$ $\mathrm{L}_{\mathrm{CP}}$ ). Fischer's $\mathrm{Z}$ tests were then computed to test for significant differences between $R^{2}$ of

\section{Figure 3}

Multiple Regression Employed in Current Study (Model 1)

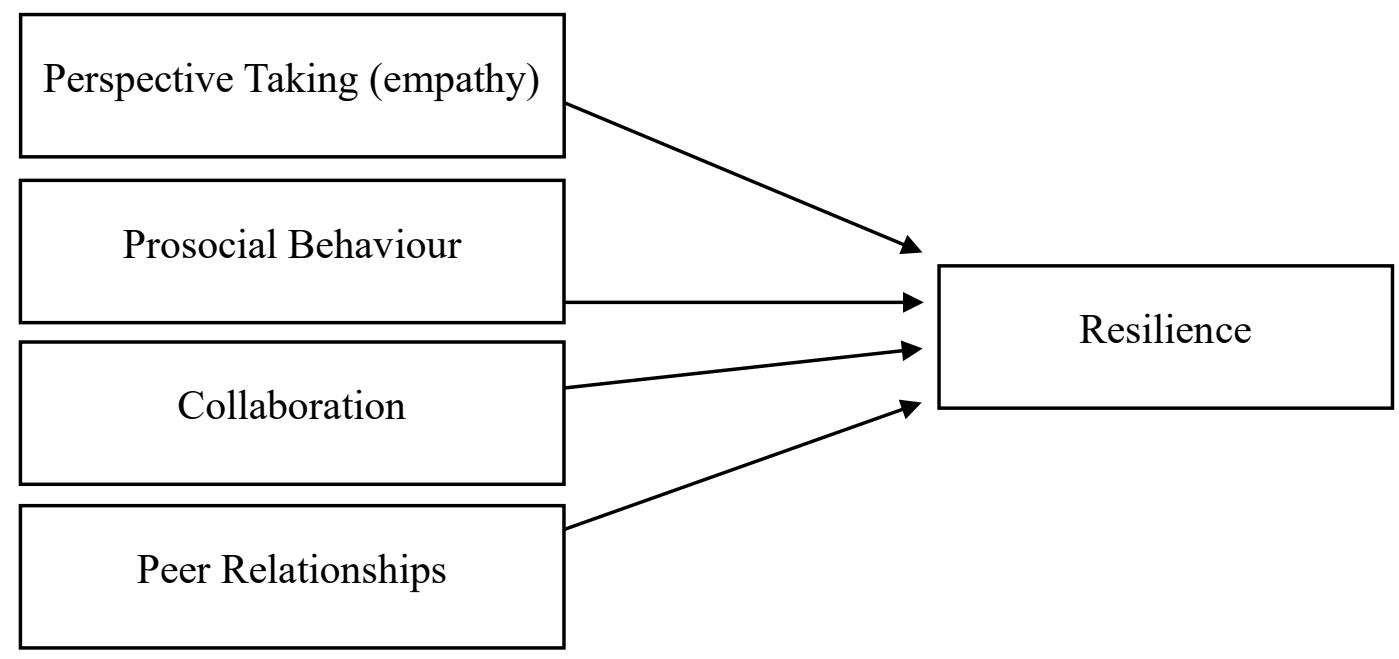

Note. Figure 3 represents Model 1. Model 2 is different by the addition of two more predictors; Year Group and Gender. 
the models for each group. Following this, a second model tested, adding gender and year group as predictors, again this model was tested individually for each group. Fischer's Z test were run to test for differences in $R^{2}$ between groups for this model and to test for differences with groups for both models. All analyses were run in the coding language R. 


\section{Chapter 3. Results}

\subsection{Descriptive Results}

Zero order correlations between all variables showed significant relationships between all variables except between Peer Relationships (-) and both Empathic Concern and Perspective Taking (see Table 2). Of the significant relationships, there were negative correlations between each of the social functioning variables (Prosocial Behaviour, Peer Relationships (-), Empathic Concern, Perspective Taking, Collaboration and Resilience) and $\mathrm{CU}$ as well as $\mathrm{CP}$. CU and $\mathrm{CP}$ were positively correlated.

\section{Table 2}

Descriptive Statistics and Correlation Matrix for the Full Sample of All Variables

\begin{tabular}{llllllllll}
\hline Variable & $M$ & $S D$ & 1 & 2 & 3 & 4 & 5 & 6 & 7
\end{tabular}

$\begin{array}{lll}\text { 1. } \mathrm{CP} & 2.80 & 2.03\end{array}$

2. CU traits $\quad 26.18 \quad 9.02 \quad .51^{* *}$

3. Prosocial Behaviour $7.30 \quad 2.05-.28 * *-.58 * *$

4. Peer relationships (-) $7.60 \quad 1.79-.32 * *-.18 * * .18 * *$

5. Empathic Concern $\quad 24.48 \quad 5.02-.32 * *-.65^{* *} \quad .55^{* *} \quad .12$

6. Perspective Taking $\quad 21.58 \quad 4.56-.28 * *-.50 * * \quad .51 * * \quad .09 \quad .59 * *$

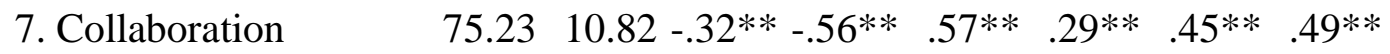

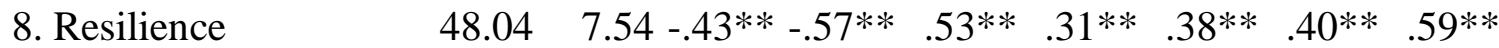

Note. Correlations are adjusted for multiple comparisons with Bonferroni's correction.

$*$ indicates $p<.05 ., * *$ indicates $p<.01$

In order to compare the four groups for social functioning variables, 6 ANOVAs were computed comparing the four groups $\left(\mathrm{H}_{\mathrm{CU}} \mathrm{H}_{\mathrm{CP}}\right.$, $\mathrm{L}_{\mathrm{CU}} \mathrm{H}_{\mathrm{CP}}$, $\mathrm{H}_{\mathrm{CU}} \mathrm{L}_{\mathrm{CP}}$, and $\left.\mathrm{L}_{\mathrm{CU}} \mathrm{L}_{\mathrm{CP}}\right)$ across Resilience, Empathic Concern, Perspective Taking, Collaboration, Peer Relationships (-) and 
Prosocial Behaviours. As can be seen in Table 3, all of these ANOVAs show a significant difference between the four groups. Tukey corrected post hoc tests indicated that for all social functioning variables, there was a significant difference between the HCU HCP group and the LCU LCP group. Table 3 describes the significant differences that did and did not occur in the last column.

\section{Table 3}

ANOVA Group Comparisons for Social Functioning Variables and Resilience

\begin{tabular}{|c|c|c|c|c|c|c|}
\hline \multirow[b]{2}{*}{ Variable } & \multicolumn{4}{|c|}{ Mean (Standard Deviation) } & \multirow[b]{2}{*}{$p$} & \multirow{2}{*}{$\begin{array}{l}\text { Significant } \\
\text { differences } \\
\text { below <.05 }\end{array}$} \\
\hline & $\begin{array}{c}\mathrm{L}_{\mathrm{CU}} \mathrm{L}_{\mathrm{CP}} \\
1\end{array}$ & $\begin{array}{c}\mathrm{HCU}_{\mathrm{CU}} \mathrm{L}_{\mathrm{CP}} \\
2\end{array}$ & $\begin{array}{c}\mathrm{LCU}_{\mathrm{CP}} \mathrm{H}_{\mathrm{CP}} \\
3\end{array}$ & $\begin{array}{c}\mathrm{H}_{\mathrm{CU}} \mathrm{H}_{\mathrm{CP}} \\
4\end{array}$ & & \\
\hline Prosocial Behaviour & $\begin{array}{c}7.93 \\
(1.64)\end{array}$ & $\begin{array}{c}5.58 \\
(2.37)\end{array}$ & $\begin{array}{c}7.09 \\
(1.83)\end{array}$ & $\begin{array}{c}5.85 \\
(2.06)\end{array}$ & $<.001 * *$ & $\begin{array}{l}2-1,4-1,3- \\
2,4-3\end{array}$ \\
\hline Peer relationships (-) & $\begin{array}{c}7.90 \\
(1.64)\end{array}$ & $\begin{array}{c}7.40 \\
(1.88)\end{array}$ & $\begin{array}{c}6.26 \\
(1.93)\end{array}$ & $\begin{array}{c}7.12 \\
(1.87)\end{array}$ & $<.001 * *$ & 3-1,4-1,3-2, \\
\hline Empathic Concern & $\begin{array}{l}26.12 \\
(4.27)\end{array}$ & $\begin{array}{l}20.70 \\
(4.01)\end{array}$ & $\begin{array}{l}23.88 \\
(5.37)\end{array}$ & $\begin{array}{l}19.88 \\
(4.69)\end{array}$ & $<.001 * *$ & $\begin{array}{l}2-1,3-1,4- \\
1,3-2,4-3\end{array}$ \\
\hline Perspective Taking & $\begin{array}{l}22.72 \\
(4.07)\end{array}$ & $\begin{array}{l}19.64 \\
(4.03)\end{array}$ & $\begin{array}{l}19.91 \\
(5.37)\end{array}$ & $\begin{array}{l}18.45 \\
(4.71)\end{array}$ & $<.001 * *$ & $\begin{array}{l}2-1,3-1,4- \\
1,\end{array}$ \\
\hline Collaboration & $\begin{array}{l}78.56 \\
(8.94)\end{array}$ & $\begin{array}{c}67.32 \\
(12.38)\end{array}$ & $\begin{array}{c}74.38 \\
(10.33)\end{array}$ & $\begin{array}{l}65.93 \\
(8.83)\end{array}$ & $<.001 * *$ & $\begin{array}{l}2-1,4-1,3- \\
2,4-3,\end{array}$ \\
\hline Resilience & $\begin{array}{l}50.76 \\
(5.71)\end{array}$ & $\begin{array}{l}42.89 \\
(7.62)\end{array}$ & $\begin{array}{l}45.41 \\
(6.92)\end{array}$ & $\begin{array}{l}40.65 \\
(8.51)\end{array}$ & $<.001 * *$ & $\begin{array}{l}2-1,3-1,4- \\
1,4-3\end{array}$ \\
\hline
\end{tabular}

Note. $*$ indicates $p<.05, * *$ indicates $p<.01$

\subsection{Correlations Between Social Functioning and Resilience by Group}

To compare relationships between each social functioning measure and Resilience, for each group separately (HCU HCP, LCU HCP, HCU LCP, and LCU LCP), correlation coefficients are represented graphically below (Figure 4-8). 
The correlations between Empathic Concern and Resilience were significant and positive for all groups except $\mathrm{L}_{\mathrm{CU}} \mathrm{H}_{\mathrm{CP}}$ (see Figure 4). $\mathrm{H}_{\mathrm{CU}} \mathrm{L}_{\mathrm{CP}}$ had the strongest positive correlation followed by $\mathrm{H}_{\mathrm{CU}} \mathrm{H}_{\mathrm{CP}}$, with $\mathrm{LCU}_{\mathrm{CU}} \mathrm{L}_{\mathrm{CP}}$ having the weakest correlation between Empathic Concern and Resilience. The correlations between Perspective Taking and Resilience were positive and significant for the $\mathrm{H}_{\mathrm{CU}} \mathrm{L}_{\mathrm{CP}}$ and the $\mathrm{L}_{\mathrm{CU}} \mathrm{L}_{\mathrm{CP}}$ groups, stronger for the $\mathrm{H}_{\mathrm{CU}} \mathrm{L}_{\mathrm{CP}}$ group (see Figure 5). The correlations between Prosocial Behaviour and Resilience were significant, positive and of a similar strength for all groups except for $\mathrm{L}_{\mathrm{CU}}$ $\mathrm{H}_{\mathrm{CP}}$ (see Figure 6). The correlations between Collaboration and Resilience once again were all significant and positive except for $\mathrm{L}_{\mathrm{CU}} \mathrm{H}_{\mathrm{CP}}$. The correlation was strongest for $\mathrm{H}_{\mathrm{CU}} \mathrm{L}_{\mathrm{CP}}$ followed by, LCU LCP groups, and then weakest for HCU HCP (see Figure 7). The correlations between Peer Relationships (-) and Resilience were significant and positive for both $\mathrm{H}_{\mathrm{CU}} \mathrm{L}_{\mathrm{CP}}$ and the $\operatorname{LCU}_{\mathrm{C}} \mathrm{L}_{\mathrm{CP}}$ (see Figure 8).

\section{Figure 4}

Correlations Between Empathic Concern \& Resilience Across CU \& CP Groups

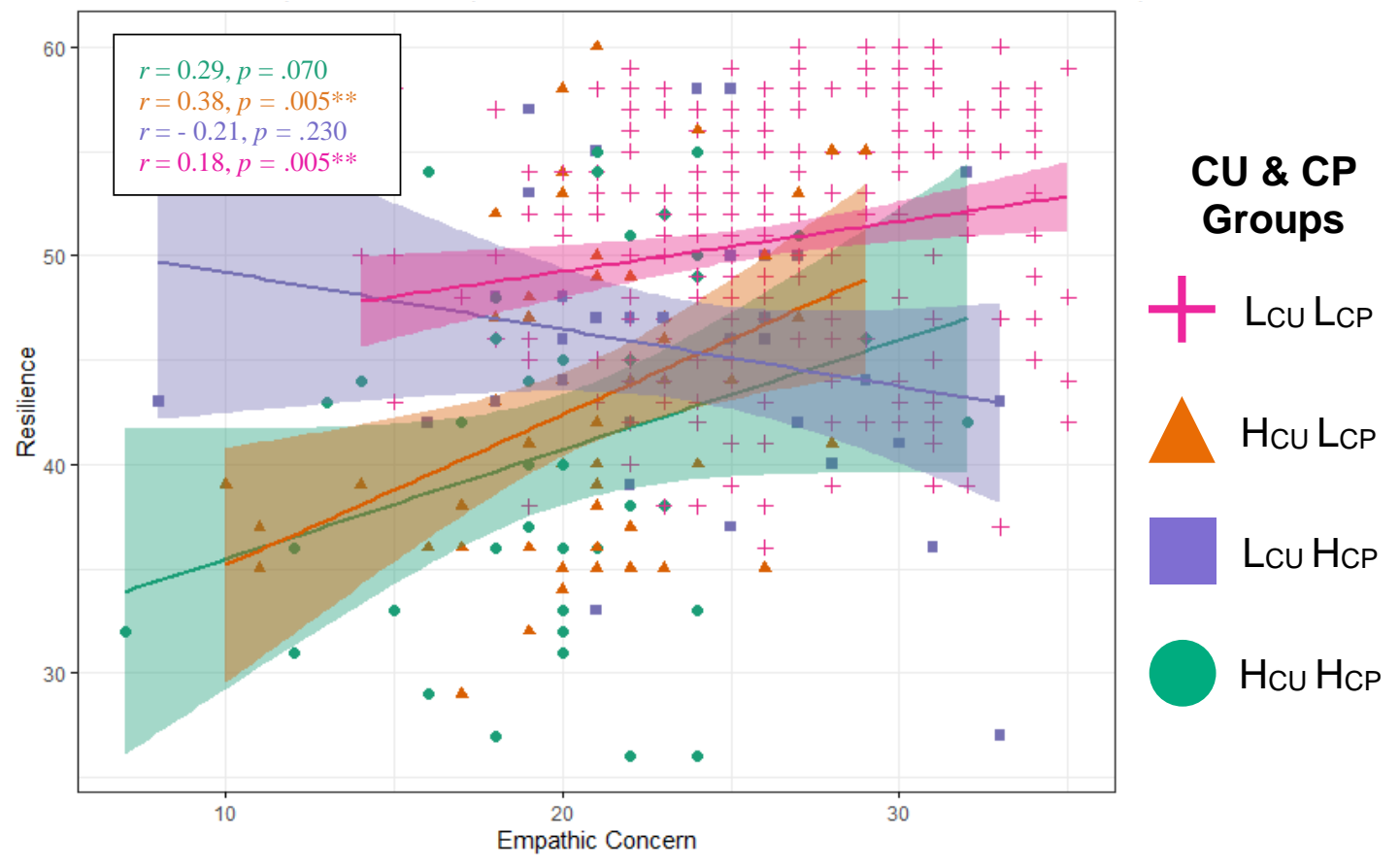

Note. * indicates $p<.05$, ** indicates $p<.0$. Shaded areas indicate error range. 


\section{Figure 5}

Correlations Between Perspective Taking \& Resilience Across CU \& CP Groups

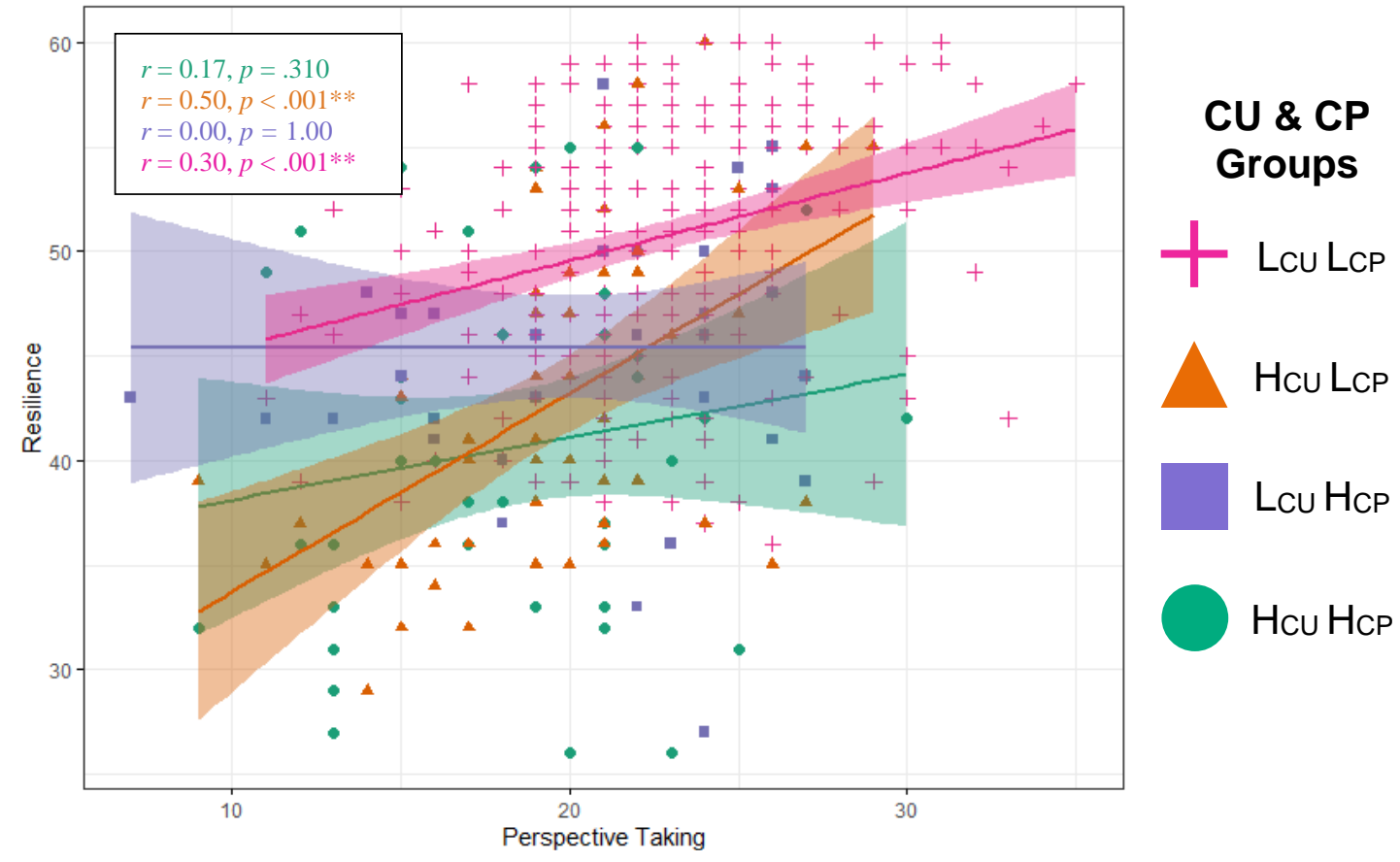

Note. $*$ indicates $p<.05$, ** indicates $p<.01$. Shaded areas indicate error range.

\section{Figure 6}

Correlations Between Prosocial Behaviour \& Resilience Across CU \& CP Groups

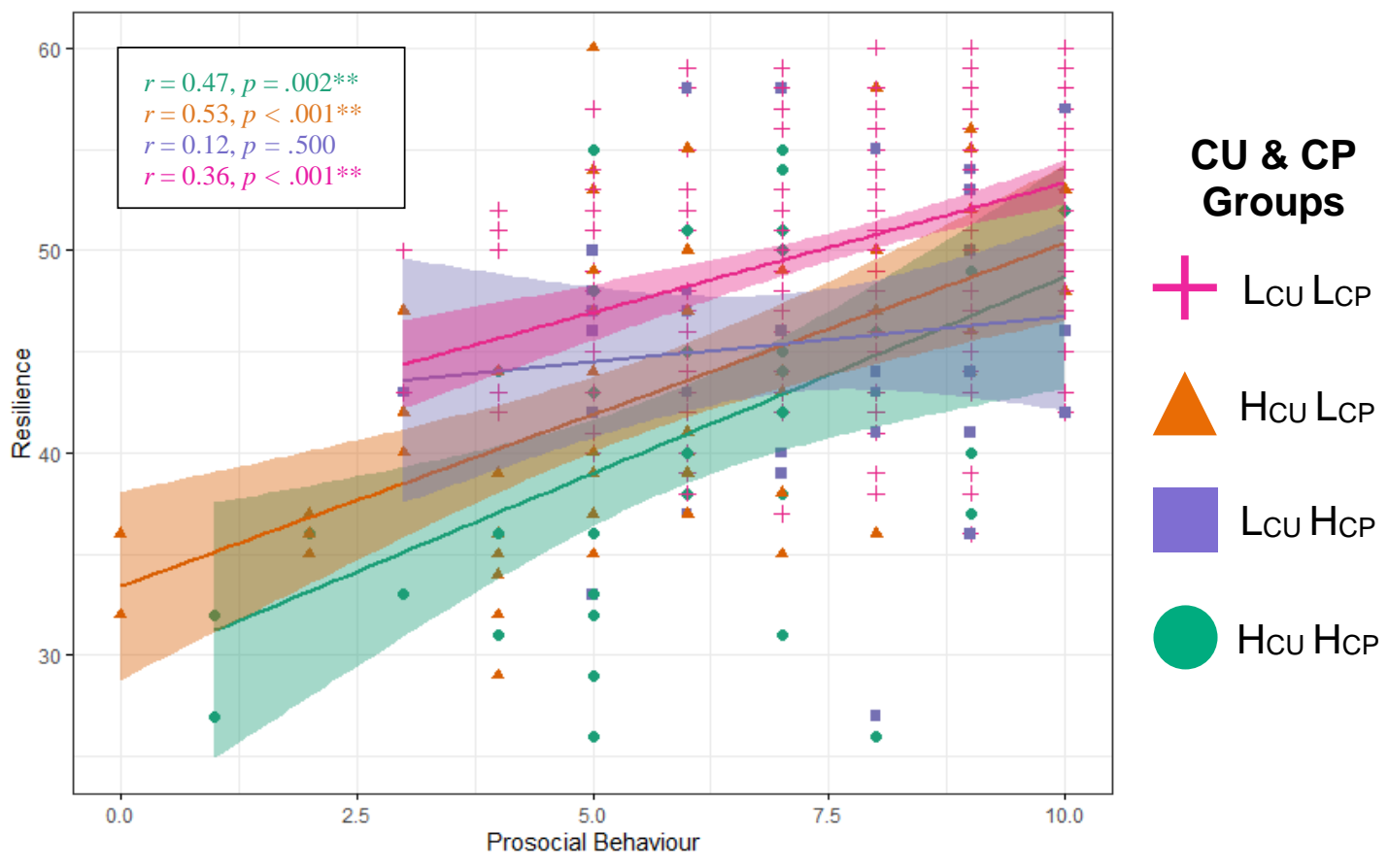

Note. * indicates $p<.05, * *$ indicates $p<.01$. Shaded areas indicate error range. 


\section{Figure 7}

Correlations Between Collaboration \& Resilience Across CU \& CP Groups

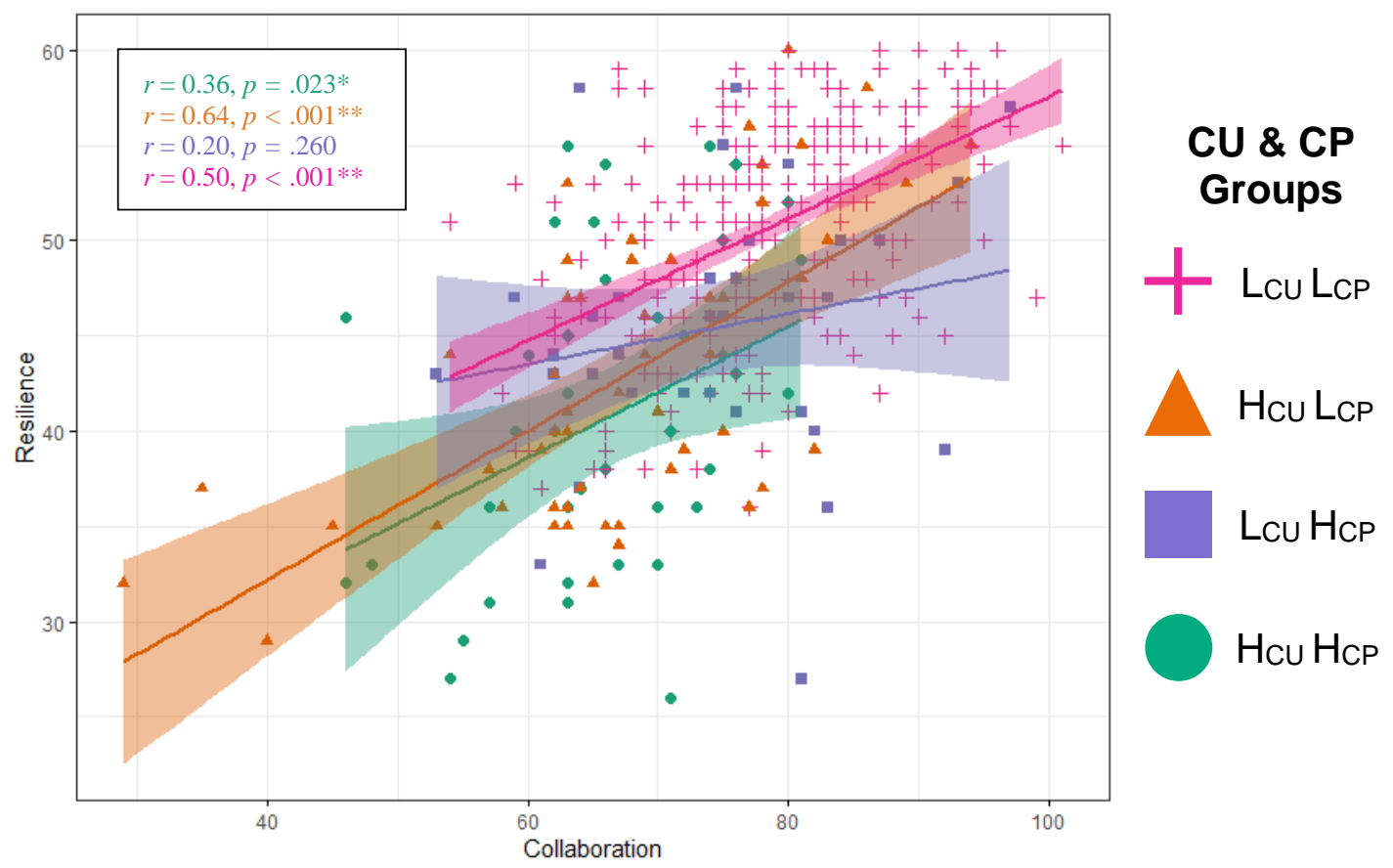

Note. $*$ indicates $p<.05, * *$ indicates $p<.01$. Shaded areas indicate error range.

\section{Figure 8}

Correlations Between Peer Relationships (-) \& Resilience Across CU \& CP Groups

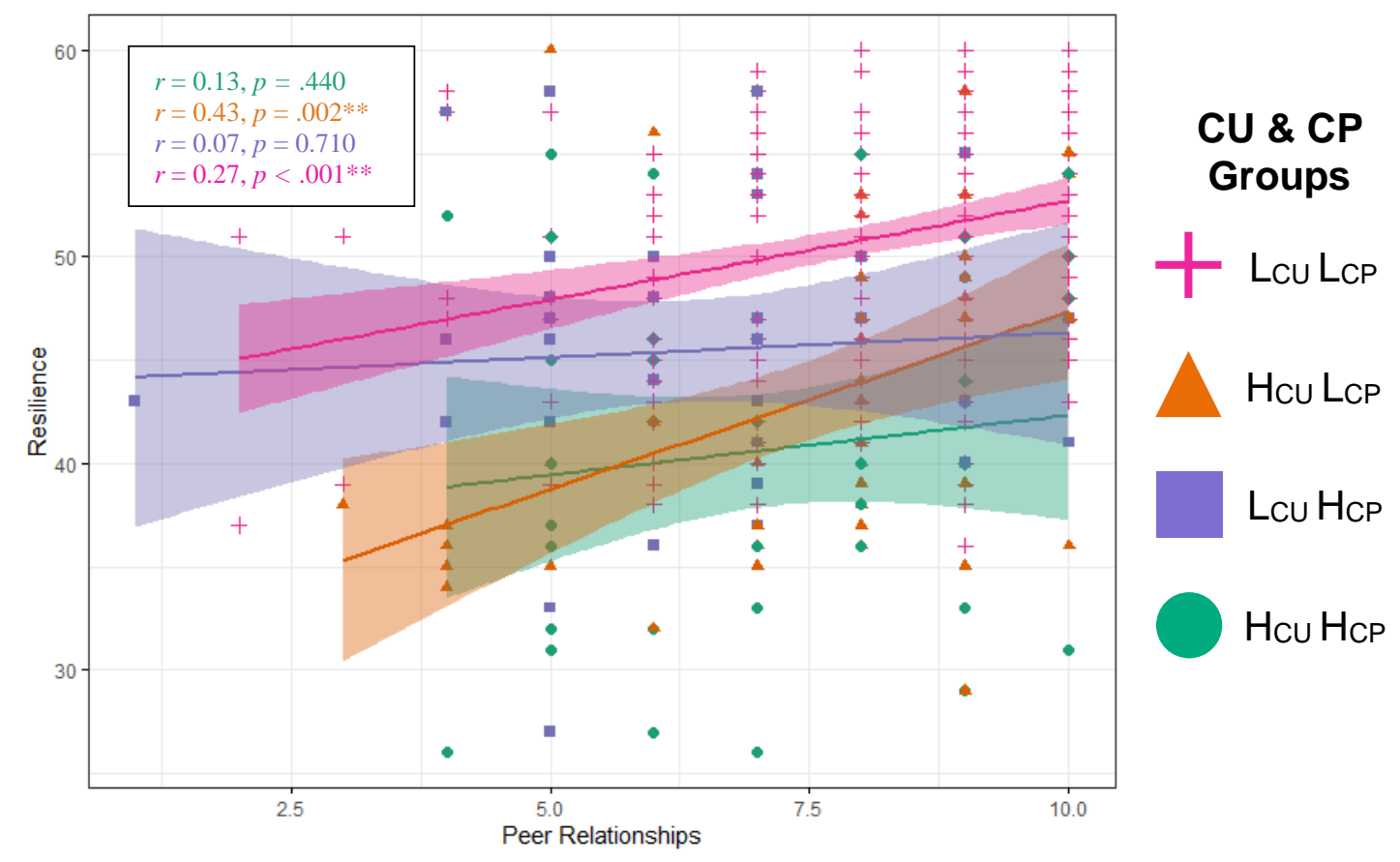

Note. $*$ indicates $p<.05, * *$ indicates $p<.01$. Shaded areas indicate error range. 


\subsection{Multiple Regression Model by Group}

Multiple regression models were conducted for each group separately. Subsequently, the $R^{2}$ values were compared to one another. This approach to analysis was chosen as it was able to show what predictors were significant for each group. This would not have been possible if the full sample was entered into the multiple regression with groups as an additional predictor. Participants whose Gender $(n=2)$ or Year Group $(\mathrm{n}=1)$ was unspecified were removed for the multiple regression analyses to allow for adding of Gender and Year Group as predictors later in Model 2.

The first model (Model 1) included the predictors Collaboration, Prosocial Behaviour, Peer Relationships and Perspective Taking and the outcome variable Resilience (Model 1). Empathic concern was not included in this model due to the conceptual overlap between this construct and CU traits. Model 1 was tested for each of the CU \& CP groups independently (see Table 4).

For the $\mathrm{LCU}_{\mathrm{C}} \mathrm{CP}$ group, about a third of the variance in resilience (36\%) was explained by the four predictor variables of collaboration, prosocial behaviour, peer relationships (-) and perspective taking. For this group Collaboration, Prosocial Behaviour and Peer Relationships (-) all were positive significant predictors, meaning that as they increased, so did Resilience.

For the $\mathrm{H}_{\mathrm{CU}} \mathrm{L}_{\mathrm{CP}}$ group, almost half the variance of Resilience (47\%) was explained by the four social functioning predictors. Within this, only Collaboration was a significant positive predictor of Resilience.

For the $\mathrm{L}_{\mathrm{CU}} \mathrm{H}_{\mathrm{CP}}$ group, Model 1 was not significant, thus Resilience was not explained by any of the four predictor variables.

For the $\mathrm{H}_{\mathrm{CU}} \mathrm{H}_{\mathrm{CP}}$ group about a quarter of the variance (26\%) in Resilience was explained by the predictors. Within this, only Prosocial Behaviour was a significant positive 
SOCIAL FUNCTIONING \& RESLIENCE IN YOUNG PEOPLE

predictor of Resilience.

Fischer's $\mathrm{Z}$ test revealed that there were no significant differences in the $R^{2}$ values between any of the four groups in Model 1 (see Table 6 in Appendix I).

Following this, gender and year group were added as predictors to investigate whether controlling for these variables would change $R^{2}$ for each group. This new model structure is called Model 2. For each group, the $\mathrm{R}^{2}$ value of Model 1 was compared to Model 2 with Fischer's Z test.

For the $\mathrm{L}_{\mathrm{CU}} \mathrm{L}_{\mathrm{CP}}$ group, again about a third of the variance in resilience (34\%) was explained by the six predictor variables of Collaboration, Prosocial Behaviour, Peer Relationships (-), Perspective Taking, Gender and Year Group. All predictors contributed significantly and positively to the model as they did for Model 1 aside from Gender and Year Group which were not significant. There was no significant difference in $R^{2}$ from Model 1 to Model 2 within the LCU LCP group (see Table 6 in Appendix I).

Similarly, for the HCU LCP group, half of Resilience's the variance (50\%) was explained by the six predictor variables. Again, only Collaboration was a significant positive predictor of Resilience. There was no significant difference between the $R^{2}$ from Model 1 and the $R^{2}$ from Model 2 within the HCU LcP group (see Table 6 in Appendix I).

For the $\mathrm{L}_{\mathrm{CU}} \mathrm{H}_{\mathrm{CP}}$ group, the $R^{2}$ value and all predictors remained non-significant and no significant differences were found between Model 1 and Model 2's $R^{2}$ values within the group (see Table 6 in Appendix I).

For the $\mathrm{H}_{\mathrm{CU}} \mathrm{H}_{\mathrm{CP}}$ group about a third of the variance (33\%) in Resilience was explained by the predictors. As with Model 1, Prosocial Behaviour was the only significant predictor of Resilience. The increase in $R^{2}$ from model 1 to model 2 was not significant based on a Fischer's Z test within this group (see Table 6 in Appendix I). 
SOCIAL FUNCTIONING \& RESLIENCE IN YOUNG PEOPLE

For model 2, Fischer's Z tests revealed no significant differences in the $R^{2}$ values between any of the groups (see Table 6 in Appendix I). 
SOCIAL FUNCTIONING \& RESLIENCE IN YOUNG PEOPLE

\section{Table 4}

Model 1 and Model 2 Multiple Regressions for All Four Groups

\begin{tabular}{|c|c|c|c|c|c|c|c|c|}
\hline \multirow[b]{2}{*}{ Predictor } & \multicolumn{2}{|c|}{$\begin{array}{c}\operatorname{LCU} \operatorname{LCP}_{(n=246)} \\
b\end{array}$} & \multicolumn{2}{|c|}{$\begin{array}{c}\mathrm{H}_{\mathrm{CU}} \mathrm{LCP}_{\mathrm{CP}}(n=53) \\
b\end{array}$} & \multicolumn{2}{|c|}{$\begin{array}{c}\mathrm{L}_{\mathrm{CU}} \mathrm{H}_{\mathrm{CP}}(n=34) \\
b\end{array}$} & \multicolumn{2}{|c|}{$\begin{array}{c}\mathrm{H}_{\mathrm{CU}} \mathrm{H}_{\mathrm{CP}}(n=40) \\
b \\
\end{array}$} \\
\hline & Model 1 & Model 2 & Model 1 & Model 2 & Model 1 & Model 2 & Model 1 & Model 2 \\
\hline & $b$ & $b$ & $b$ & $b$ & $b$ & $b$ & $b$ & $b$ \\
\hline (Intercept) & $19.18 * *$ & $19.31 * *$ & $13.23^{*}$ & 12.95 & $36.03 * *$ & $62.76^{* *}$ & 16.76 & 16.25 \\
\hline Collaboration & $0.22 * *$ & $0.21 * *$ & $0.23 *$ & $0.25 *$ & 0.12 & 0.11 & 0.15 & 0.13 \\
\hline Prosocial Behaviour & $0.70 * *$ & $0.76^{* *}$ & 0.41 & 0.57 & 0.20 & 0.68 & $1.58 *$ & $1.52 *$ \\
\hline Peer Relationships (-) & $0.71 * *$ & $0.72 * *$ & 0.79 & 0.51 & 0.11 & -0.01 & 0.54 & 0.51 \\
\hline Perspective Taking & 0.13 & 0.15 & 0.31 & 0.32 & -0.10 & -0.14 & 0.06 & 0.15 \\
\hline Gender & & 0.88 & & 2.95 & & 0.43 & & 4.87 \\
\hline Year Group & & -0.10 & & -0.23 & & -3.29 & & -0.28 \\
\hline$R^{2}(95 \% \mathrm{CI})$ & $\begin{array}{c}.36 * * \\
(.23, .41)\end{array}$ & $\begin{array}{c}.34 * * \\
(.23, .41)\end{array}$ & $\begin{array}{c}.47 * * \\
(.22, .59)\end{array}$ & $\begin{array}{c}.50 * * \\
(.20, .60)\end{array}$ & $\begin{array}{c}.05 \\
(.00, .12)\end{array}$ & $\begin{array}{c}.15 \\
(.00, .23)\end{array}$ & $\begin{array}{c}.26^{*} \\
(.00, .41)\end{array}$ & $\begin{array}{c}.33 * \\
(.00, .45)\end{array}$ \\
\hline
\end{tabular}

Note. The difference between Model 1 and Model 2 is the addition of Year Group and Gender as predictors. $b=$ Unstandardized Beta

Weights * indicates $p<.05, * *$ indicates $p<.01$. 


\subsection{Exploratory Validity Analysis for the IRI Questionnaire}

Further exploratory analysis was undertaken to investigate the unexpected nonsignificant relationships between the empathy measures (Perspective Taking \& Empathic Concern) and Resilience across groups. Empathic Concern and Perspective Taking were not significant predictors in any of the four multiple regression models.

In order to investigate the potential validity issues of the scale we computed a confirmatory factor analysis (CFA) for the full Empathy measure (IRI), including the four subscales of Empathic Concern, Perspective Taking, Fantasy and Personal Distress. A CFA including the full sample showed non satisfactory fit indices for the four-factor model (see Table 5).

Table 5

Comparison of Confirmatory Factor Analysis Fit for the Four-Factor Model of the IRI

\begin{tabular}{cccccc}
\hline & $\begin{array}{c}\text { Sample } \\
\text { Size }\end{array}$ & CFI & TLI & RMSEA & $\begin{array}{c}\text { RMSEA 90\% } \\
\text { CI }\end{array}$ \\
\hline $\begin{array}{c}\text { Current study } \\
\text { Chrysikou \& Thompson } \\
(2016)\end{array}$ & 374 & 0.730 & 0.702 & 0.080 & {$[.075,0.085]$} \\
\hline
\end{tabular}

Note . $\mathrm{CFI}=$ comparative fit index TLI $=$ Tucker - Lewis index $;$ RMSEA = root mean square error of approximation; $\mathrm{CI}=$ confidence interval.

In comparison to previous findings on the model fit for the IRI, the current study has worse model fit (see Table 5). Whilst the current study's RMSEA is better than Chrysikou and Thompson (2016), all measures of model fit are acceptable for their research compared to only the RMSEA being acceptable in the current study (Hooper et al., 2008). 


\section{Chapter 4. Discussion}

This study investigated how social functioning (Perspective Taking, Empathic Concern, Prosocial Behaviour, Peer Relationships (-) \& Collaboration) predicted resilience across four groups varied on levels of callous-unemotional traits (CU) and conduct problems (CP). The four groups varied on high $(\mathrm{H})$ and low $(\mathrm{L})$ levels of $\mathrm{CU}$ and $\mathrm{CP}$. The groups were HCU HCP, LCU HCP, HCU LCP, and LCU LCP. Results showed that for all groups, aside from LCU $\mathrm{H}_{\mathrm{CP}}$, as each social functioning variable increased, Resilience tended to increase as well. A key finding of the study was that social functioning explains approximately half of variance in Resilience for the $\mathrm{H}_{\mathrm{CU}} \mathrm{L}_{\mathrm{CP}}$ group, approximately a third of the variance for the $\mathrm{L}_{\mathrm{CU}} \mathrm{L}_{\mathrm{CP}}$ group and about a quarter for the $\mathrm{H}_{\mathrm{CU}} \mathrm{H}_{\mathrm{CP}}$ group. However, none of these $R^{2}$ differed significantly from each other. Nor did the addition of Gender or Year Group as a predictors significantly change $R^{2}$ values for any group or change what predictors were significant in each model.

\subsection{Pattern of Strong Results for High Callous-Unemotional Traits Low Conduct Problems Group}

One finding of interest is the strong pattern of significant results seen for in the $\mathrm{H}_{\mathrm{CU}}$ LCP group. This group had the strongest correlations between each social functioning variable and Resilience and, for both multiple regression models, the $\mathrm{H}_{\mathrm{CU}} \mathrm{L}_{\mathrm{CP}}$ group explained approximately half of the variance in Resilience. This suggests that social functioning is very relevant to resilience for individuals with high levels of CU traits without high $\mathrm{CP}$ trait. The fact that these results were not the same for the $\mathrm{H}_{\mathrm{CU}} \mathrm{H}_{\mathrm{CP}}$ group suggests that there is something unique about the combination of high $\mathrm{CU}$ and low $\mathrm{CP}$ rather than this result being about anyone with high CU. Potentially, individuals high only on $\mathrm{CU}$ (and not $\mathrm{CP}$ ) have higher quality social functioning as they do not experience the same social impairment as in CP (Wall et al., 2016 Eisenbarth et al., 2016). This may mean they are greater able to use 
social skills to access support in a way that the presence of high $\mathrm{CP}$ would block. This fits with research by Wall et al. (2016) who found that children high on CU traits rated themselves as more connected to their school than those high on both CU and CP. This also fits with research by Miron et al. (2020) whose results suggested healthy friendships might decrease CU levels, indicating that social functioning can influence CU as well. Both studies also considered the possibility that encouraging better social functioning might work as an intervention and alleviate difficulties in CU and CP. Potentially, social connections play a role in building resilience for those high in $\mathrm{CU}$ (without $\mathrm{CP}$ ) and for those with neither trait, whereas the antisocial behaviours associated with $\mathrm{CP}$ function as barriers to social connection. This would fit with research by Fanti et al. (2017) who found that individuals with decreasing levels of CU across time had similar levels of peer social support and connectedness as individuals deemed as low risk (although critically this research did not control for $\mathrm{CP})$.

Alternatively, potentially the pattern of results for the $\mathrm{H}_{\mathrm{CU}} \mathrm{L}_{\mathrm{CP}}$ can be explained by the current study's conceptualisation of social functioning. Pardini and Fite (2010) suggest that the social difficulties seen in both $\mathrm{CU}$ and $\mathrm{CP}$ are associated with more deviant peer group associations rather than with peer conflict. In the current study, social functioning is conceptualised more around ordinary peer relationships and not deviant peer groups or aggression. Potentially, the strong relationship between social functioning and resilience for those with high CU is a reflection of conceptualising social functioning in a manner which presents as less impaired for individuals with high $\mathrm{CU}$ alone due to a focus on skills rather than quality or nature of relationships. This would fit with research by Muñoz et al. (2008) who found that youth who were high on psychopathic traits still had stable and mutual friendships, but the nature of these friendships involved antisocial behaviour. It is possible that the measures of social functioning in the current study were more embedded in the 
presence of ordinary peer relations or social skills, which are more associated with difficulty in $\mathrm{CP}$, than in the peer conflict or aggression which appears more associated with difficulties in CU. For example, Viding et al. (2009) found that individuals high on CU and not CP show more proactive aggression (i.e. confrontational rather than covert behaviours) due to more easily withstanding another's distress. Further research in this area should measure a broader range of social behaviours in order to be more sensitive to how social difficulties present differently across individuals high in $\mathrm{CU}$ or $\mathrm{CP}$.

Furthermore, this might mean different results would have been found if our measures of social functioning paid further attention to aggression or the nature of participants friendships rather than just the ability to get along with friends and peers. Indeed, Backman et al. (2018) found that the quality of a relationship was more important that the presence of a relationship when it came to young people with psychopathic traits and the influence of peers. Additionally, this study suggested that both the peer environment and the family environment are contributors to CP (Dodge \& Pettit, 2003). However, research by van Harmelen et al. (2017) found that friendship support was a predictor of immediate and future resilient psychosocial functioning whereas family support was only a predictor of immediate family support. Taken together, this might suggest that the peer social environment plays a stronger role for young people than the family social environment. However, van Harmelen et al.'s study did not consider differences based on CU and CP making it difficult to know whether social functioning within the family might play out differently for the current study's four groups of CU and CP individuals. Either way, although it was beyond the scope of the present study to investigate the social patterns of participants' families, these relationships are still likely playing a role in the development and expression of $\mathrm{CP}$ and, subsequently, also in the shaping the social environment a young person will end up in. Drawing this research all together, it is possible the pattern of results seen in the $\mathrm{H}_{\mathrm{CU}} \mathrm{L}_{\mathrm{CP}}$ group may be explained by 
the current study focusing on variables related to the presence of social connections and skills rather than considering social functioning more broadly by including elements like aggression, relationship quality or family social functioning.

\subsection{The Role of Collaboration in Resilience}

Collaboration played a stronger role in predicting Resilience than anticipated in the current study. It was one of several significant predictors for the Lcu LcP group and the only significant predictor for the $\mathrm{H}_{\mathrm{CU}} \mathrm{L}_{\mathrm{CP}}$ group. However, it was not significant for either $\mathrm{H}_{\mathrm{CU}}$ $\mathrm{H}_{\mathrm{CP}}$ or $\mathrm{L}_{\mathrm{CU}} \mathrm{H}_{\mathrm{CP}}$. Additionally, Collaboration had a significant correlation with Resilience for each of the $\mathrm{L}_{\mathrm{CU}} \mathrm{L}_{\mathrm{CP}}, \mathrm{H}_{\mathrm{CU}} \mathrm{L}_{\mathrm{CP}}$ and $\mathrm{H}_{\mathrm{CU}} \mathrm{H}_{\mathrm{CP}}$ groups. These significant positive correlations and predictor variables in the models suggest that collaboration is a skill which allows for greater resilience to develop, regardless of CU levels but only when $\mathrm{CP}$ is low.

Potentially, the lack of Collaboration as a significant predictor in the model for both groups with high levels of $\mathrm{CP}$ might suggest that $\mathrm{CP}$ is a barrier to collaboration increasing resilience. Potentially the presence of $\mathrm{CP}$ prevents individuals from building the types of relationships with others where collaboration would ordinarily occur. Alternatively, it might be that for individuals with higher level of $\mathrm{CU}$, collaboration is a means to access further benefits which promotes greater resilience without a prosocial or mutually beneficial attitude towards collaborating. For example, potentially individuals with high $\mathrm{CP}$ cannot make the link between collaboration and resilience due to a pre-existing lack of peer relationships. Whereas individuals with high CU potentially can see and choose to collaborate with peers when they are able to see a gain. Although this would not be purely 'prosocial', it still allows for collaborative skills to be built and practiced. This leads to the question of whether collaboration in $\mathrm{CU}$ is mutually beneficial or whether the current Collaboration scale is sensitive to collaborative behaviours for personal, non-collaborative gain. 
Alternatively, the strong results for collaboration in the current study might reflect overlap in the collaboration and resilience constructs. This is because the attitudes or acts required for collaboration are similar to those required for resilience within low $\mathrm{CP}$ groups (i.e. accessing community or peer support). The correlation between these two constructs across the whole sample was strong and positive $(r=0.59, p<.05)$ potentially indicating an overlap in scale content. Indeed, both measures include some items about knowing where to get support from or how to work with others. However, the fact that the correlation was not perfect (or near to perfect) indicates that there are still some independent features in each construct. To our knowledge, there is no research investigating whether collaboration and resilience are linked processes or skills so the extent of these constructs' overlap is not known. This is an area for future research as the same skills that allow for greater collaboration (accessing goods, working with others, mutual support) also appear related to increased resilience.

\subsection{Perspective Taking and the Interpersonal Reactivity Index}

Perspective Taking was surprisingly not a significant predictor in any model. Potentially this is due to this skill being more internalised and individual. In comparison, the predictors that came out significant tended to measure relationships with others or the attitudes towards these relationships. This might suggest that in young people who vary on $\mathrm{CU}$ and $\mathrm{CP}$ traits, resilience is fostered more by the social dynamics around someone rather than by their individual capacity to perspective take. This suggests that the social aspect of resilience within a biopsychosocial model is more relevant for certain populations (Vella \& Nagesh, 2019; Herrman et al., 2011). And in turn, emphasises that resilience is not a uniform process for all people but can vary depending on different traits (Vella \& Nagesh, 2019; Herrman et al., 2011). 
Alternatively, there are several factors related to the measures used in the study that might explain the absence of an effect for Perspective Taking. Firstly, the Child and Youth Resilience Measure - 12 (CYRM-12) focuses more on the social elements of resilience which may be more closely related to the outward elements of social functioning (i.e. the presence of relationships) rather than internally focused skills such as perspective taking. Potentially, if the CYRM-12 had a better consideration of the psychological/individual features of resilience, Perspective Taking might have had a significant relationship.

Alternatively, it might be that Perspective Taking is a less salient skill than the other aspects of social functioning being asked about in this study. Reporting Perspective Taking likely requires a greater level of metacognition than reporting the more overt and more salient presence of social relationships. This might mean the Perspective Taking scores are more uncertain and less reliable due to scores being more affected by metacognitive ability. Whilst still possible, this explanation seems less likely as the means and standard deviations of Perspective Taking still shows that participants responded within the scope of expected scores (see Table 3 ).

It is also possible that the lack of effect for Perspective Taking's reflects the Interpersonal Reactivity Index's (IRI) poor model fit. Indeed, within this sample, all variables had significant correlations with each other (both positive and negative) except for between each of Perspective Taking and Empathic Concern's correlations with Peer Relationships (-). This was surprising and might suggest the subscales of the IRI are not measuring their constructs validly in this sample. Still, both variables showed were correlated with each other and, as expected, Empathic Concern was significantly and negatively correlated with CU traits. Despite this, confirmatory factor analysis indicated that, for the current study, the fourconstruct model was not satisfactory unlike the IRI is in other samples (Hooper et al., 2008; Chrysikou \& Thompson; 2016). This suggests that the four constructs (Empathic Concern, 
Perspective Taking, Personal Distress and Fantasy) are not structured as designed in this population. This may mean that the measure of Perspective Taking in the study, is not validly measure Perspective Taking but instead some combination of empathetic skills. This in turn may be able to explain why Perspective Taking was not contributing to Resilience in the current study as expected.

\subsection{Strengths of the Study}

One strength of the study is how participants were sampled. Due to all coming from the same school, participants were more likely to have shared social factors such as community resources, educational experiences and supports. This increases the homogeneity of the sample and likely reduces noise that could hide or cancel out possible results. Additionally, because students participated in the study through an opt-out methodology, this study likely captured a greater range of participants than it would have if the study had been opt-in. This reduces the participation bias of the current study. Taken together, these two factors add to the strength of the study because the sample is more attuned to pick up on effects that may have otherwise been hidden amongst noise.

Another strength of the current study is the decision to employ the Child and Youth Resilience Measure - 12 (CYRM-12; Lyneham et al., 2008). This measure has been validated in a variety of samples including in disadvantaged children (Liebenberg et al., 2013; Russell et al., 2021). It has also been shown to measure resilience across age and gender accurately (Renbarger et al., 2020). Whilst this study also suggested that it does not measure resilience as well across different communities, this less likely to be an issue within the current study due to all participants coming from the same school and so reflecting a similar community already. Moreover, the CYRM-12 takes a broader, environmental view to resilience which is consistent with the current understanding that resilience is not an individual trait but a dynamic biopsychosocial process (Luthar \& Cicchetti, 2000). For this reason, the study's 
choice to employ the CYRM-12 to measure resilience allows for the resilience construct to be measured in a way that is aligned to current understandings of what resilience is and how it works.

A further strength of the current study is its decision to run the model structure for each group individually. In doing this, the pattern of significant predictor variables was able to be seen for each group uniquely. This would not have been possible if the group allocation had been added as an additional predictor variable in a single model. In taking this approach to analysis, it was possible to view unique patterns as different across the groups. For example, it was seen that Collaboration was a significant predictor for the both the $\mathrm{H}_{\mathrm{CU}} \mathrm{L}_{\mathrm{CP}}$ and $\mathrm{L}_{\mathrm{CU}} \mathrm{L}_{\mathrm{CP}}$ groups but not for $\mathrm{L}_{\mathrm{CU}} \mathrm{H}_{\mathrm{CP}}$ or $\mathrm{H}_{\mathrm{CU}} \mathrm{H}_{\mathrm{CP}}$. Understanding these unique predictors allow for understanding more specifically how each of the four groups in the current study, differ from each other.

Additionally, the current study is strengthened by the decision to investigate the relationship between collaboration and resilience. From our review of the literature, collaboration appears to be a neglected area of research in the area of young people with $\mathrm{CU}$ and CP traits. Collaboration's inclusion in the current study is beneficial as it was revealed to be correlated with increased resilience for individuals in the $\mathrm{HCU}_{\mathrm{C}} \mathrm{L}_{\mathrm{CP}}$, $\mathrm{H}_{\mathrm{CU}} \mathrm{HCP}_{\mathrm{CP}}$ and $\mathrm{LCU}_{\mathrm{C}} \mathrm{LP}$ groups and to be a significant predictor within the model for both $L_{C U} L_{C P}$ and $H_{C U} L_{C P}$. Revealing these links is helpful as it opens several new avenues for research such as how collaboration might differ in young people based on $\mathrm{CU}$ and $\mathrm{CP}$ and how greater collaboration might contribute to greater resilience.

\subsection{Implications}

Firstly, this study suggests that better social functioning is linked to increased resilience, although the exact aspects of social functioning which are important, depend on the nature of $\mathrm{CU}$ and $\mathrm{CP}$ for any given individual. It is possible that by encouraging stronger 
social functioning in young people, these individuals develop more skills, connections or other abilities which encourage greater resilience. This fits with Wilkinson et al. (2016) who found that social skills training tended to work alongside other treatments in reducing CU traits. Moreover, the possibility of social functioning as an intervention for CU and CP has been suggested by both Miron et al. (2016) and Wall et al. (2016) who found that increased social functioning was associated with decreased CU traits. Taken together, this previous research and the current study suggest that interventions conducted alongside social skills training might be more effective as the social contexts helps build resilience concurrently. Moreover, these findings suggest that where possible, interventions should be conducted in a way that allows individuals to maintain their social connections, if prosocial, to allow for resilience to still be drawn upon within treatments. Framed another way, this suggests that removing young people with $\mathrm{CU}$ and/or $\mathrm{CP}$ from their social context, removes them from an environment that might facilitate more resilience. This is a strong argument in favour of treatments being embedded in social context an individual lives within.

This study also emphasizes the need to consider the population of young people with varying levels of $\mathrm{CU}$ and $\mathrm{CP}$ as heterogeneous. The four groups in the study, classed as a combination of high and low $\mathrm{CU}$ and $\mathrm{CP}$, showed differences in how social functioning variables predicted resilience. This is even within a more homogenous sample where individuals were sampled from the same school and similar year groups. When an individual was low on both domains, Collaboration, Prosocial Behaviour and Peer Relationships (-) were all significant predictors, whereas when an individual was high on both, only Prosocial Behaviour was a significant predictor. Most crucially, there were different patterns when individuals were high on one of these traits but not the other, which were different again to when individuals were high on both. Research by Frick et al. (2014a) found that by grouping individuals as having high levels of $\mathrm{CP}$ or high levels of both $\mathrm{CP}$ and $\mathrm{CU}$, without any group 
for individuals displaying high CU alone, effects unique to the interplay of each trait cancelled out and were not visible in the results. Our study reiterates this point, showing that each of the four ways $\mathrm{CU}$ and $\mathrm{CP}$ were grouped here led to differences in how social functioning related to resilience.

\subsection{Limitations of Study}

A limitation is the current study's grouping of CU and CP traits. Due to the nature of the data, CU and CP scores were used to create four groups where individuals were either high (top 25\%) or low (bottom 75\%) on either of the two traits. A main issue with this approach is that it does not consider the trajectory or onset of each construct. Bevilacqua et al.'s (2018) systematic review of CP trajectories showed that those with early onset, but persistent CP had worse outcomes than individuals with adolescent onset, or childhoodlimited CP (outcomes were measured by mental health, substance use, general health, employment/education and crime). In the current study, different onset/trajectories could not be teased out for the group of $\mathrm{H}_{\mathrm{CP}}$ adolescents due to the cross-sectional nature of the data. This means that if there was a difference in the relationship between social functioning and resilience for the three groups of early onset persistent $\mathrm{CP}$, adolescent onset $\mathrm{CP}$ and childhood limited CP, the current study would not be able to identify this.

This is an important consideration as early onset persistent CP may prevent individuals from learning social skills in way that does not occur for adolescent onset CP. Accordingly, because of these differences in opportunity across the lifetime, there may be differences in how these groups function socially and use that social functioning to form greater resilience which the current study cannot pick up upon. Additionally, the nature of childhood limited CP may mean individuals do not have access to social resources in childhood, and so develop alternative ways to build resilience without social functioning. However, considering that research in this field, does not always differentiate between those 
with high CU alone, and those with high CU and CP, the current study's use of four groups in this way is still able to contribute to the literature even without considering trajectories and onset.

An additional problem with the current study is the approach to creating high and low groups based on percentage derived cut-offs. Participants were allocated to high and low CU and CP based on whether they were in the top $25 \%$ of the sample (high) or bottom $75 \%$ of the sample (low). This means that the group allocation could be skewed if the sample was as a whole, higher or low on each trait than reasonably expected for a school. Clinical thresholds were not able to be used due to the survey nature of the study and the use of a school sample rather than a clinical or forensic sample. The percentage cut-offs created a hard threshold between low and high that may not actually represent the level of behavioural and emotional difficulties seen in $\mathrm{CU}$ and $\mathrm{CP}$. This is especially considering that the range of scores for $\mathrm{CP}$ on the SDQ is 0-10 which may mean the scale is less sensitive to meaningful differences in scores. Moreover, the SDQ is not a diagnostic tool for CP and so high CP scores on this scale cannot guarantee $\mathrm{CP}$ is indeed present. For this reason, it would be of interest to investigate the relationship between social functioning and resilience in a clinical or forensic population as this may more validly depict the nature of $\mathrm{CU}$ and $\mathrm{CP}$ than can be done within a general population sample and with psychometric scales.

Another limitation to the current study is that it was sampled from one high-school in the United Kingdom. This may narrow the sample into a more homogenous group due to living in the same area, having shared experiences at school itself and potentially sharing similar community resilience factors. Whilst this homogeneity is also a strength in noise reduction, it does mean that the results might not generalise well to other populations. In order to overcome this limitation, similar studies with differing samples would be useful to ensure that the current study's results can be replicated elsewhere. 


\subsection{Future Directions}

This study has introduced a range of possible research avenues. A first step would be to replicate the current study's approach within different samples to see if the same effects hold for different populations. As part of this, it would be useful to use a sample built from individuals with clinical or forensic levels of CU and CP as this would show whether school samples can continue to be used to represent clinical samples. This is turn would be helpful for running further studies as conducting research with clinical populations tends to be more time-consuming and costly. This method of sampling would also hopefully allow for a more equal spread of participants across the four groups unlike the current study.

To get this forensic and clinical population, sampling would likely have to occur through intervention services (e.g., parenting programmes, multisystemic therapy, youth justice services). It would also require deciding on an objective threshold for having high CU and high $\mathrm{CP}$ rather than relying on a population based split as in the current study (bottom $75 \%=$ low, top $25 \%=$ high). This approach would allow for the current study's findings to be tested in populations more severe levels of $\mathrm{CU}$ and $\mathrm{CP}$, which is likely where interventions to increase resilience would be aimed. This approach to sampling would also help reveal whether the pattern of strong results seen for the group high on only CU (and not $\mathrm{CP}$ ) was an artefact of the sample used, or is indeed whether this link between social functioning and resilience continues when the $\mathrm{HCU}_{\mathrm{C}} \mathrm{L}_{\mathrm{CP}}$ is based on clinically significant populations. However, it would likely be difficult to recruit individuals for the group high on $\mathrm{CU}$ but low on $\mathrm{CP}$ as these individuals are engaging in less antisocial behaviour and so may not have come to the attention of clinical or forensic services.

Another positive of sampling in this way is that there would be more variability in the communities that participants come from and thus represent a range of different societal support levels. This would be useful as the current study's approach of sampling from one 
school may mean all participants had access to similar community resources. If possible, longitudinal data could be collected to see whether the link between social functioning and resilience changes for young people of different $\mathrm{CU}$ and $\mathrm{CP}$ onsets and trajectories as groups formed in this way, display different patterns of difficulty and outcomes than when sampled concurrently (Frick \& Kemp, 2020; Bevilacqua et al., 2018). This is a richer way to understand the nature of $\mathrm{CU}$ and $\mathrm{CP}$ as it gives information about what difficulties preceded the other, the chronicity or stability of the difficulties and whether the difficulties have been resistant to intervention.

Alternatively, the current study could also be further developed by including a wider range of variables explore different aspects of social functioning. For example, incorporating measures of aggression as part of the scope of social functioning, might be more sensitive to the quality of relationships between peers. This also would provide insight into how different forms of aggression, associated differentially with $\mathrm{CU}$ and $\mathrm{CP}$, work as a barrier to accessing resilience (Waller et al., 2017; Eisenbarth et al., 2016). In the current study, the measure Prosocial Behaviour begins to consider this in part but without the specificity of different forms of aggression. Additionally, having a measure that specifically looks at social skills and social problem solving would allow for greater understanding around whether it is the relationships themselves that drive better resilience or rather whether it is the underlying skills which allow for better relationships that also contributes to better resilience.

Another direction of interest following the present study is the positive correlation between collaboration and resilience. These two constructs hold similar ideas of working with others to achieve more or to access supports and resources. Particularly of interest in the current study was the finding that Collaboration was the only significant predictor of Resilience when the group that was high on CU and low on CP. Future research could investigate the mechanism of how collaboration is associated with greater resilience, and how 
this relationship changes across different populations. For example, it would be interesting to know whether teaching children how to collaborate at school promotes greater resilience due to an overlap in the skills required for both or whether collaboration strengthens social relationships which in turn provides more social opportunities for resilience to be harnessed. Moreover, considering Collaboration was a predictor of Resilience for those with high CU, it would be interesting to build a richer understanding of what collaboration involves for individuals with high levels of CU traits. Potentially they collaborate in an exploitive manner to access better grades or resources, or potentially, collaboration helps override the more selffocused behaviours associated with greater CU. Either way, understanding how individuals with CU function in collaborative school environments would be of interest.

\section{Concluding Remarks}

Resilience is a dynamic process which allows individuals to achieve positive outcomes where they would have otherwise been at risk for worse outcomes. Often resilience becomes the focus of attention as way to help divert high risk individuals from trajectories that lead to worse outcomes. For this reason, the current study investigated whether better social functioning is linked to increased resilience, as this link might provide a future way to intervene on negative trajectories. Moreover, young people with either or both high levels of callous-unemotional (CU) traits and conduct problems $(\mathrm{CP})$, tend to have worse social functioning which leads to the question; if social functioning tends to promote more resilience, does this continue to occur for individuals with $\mathrm{CU}$ and/or $\mathrm{CP}$ ?

Multiple regressions conducted with Collaboration, Prosocial Behaviour, Peer Relationships and Perspective Taking as predictors for Resilience showed that whilst Resilience still is predicted by social functioning in individuals with $\mathrm{CU}$ and $\mathrm{CP}$, the specific predictors in this relationship change depending on whether someone shows both high levels 
of $\mathrm{CU}$ and $\mathrm{CP}$, neither or just one of these traits. Notably, about half of the variance in Resilience was explained by the social functioning variables for individuals who were high on $\mathrm{CU}$ (and not $\mathrm{CP}$ ). This might suggest that for individuals showing these CU traits, social functioning has more of a role to play in increasing resilience. Future studies should continue to address the link between social functioning and resilience in forensic and clinical populations, and especially in this HCU LCP group, to help understand whether there is a causal mechanism that can be intervened upon to increase resilience.

The results also continue to emphasise a need to consider the interplay of CU traits and $\mathrm{CP}$ when researching either one. This study adds to a growing body of work that suggests looking at individuals with $\mathrm{CP}$, without considering also whether or not they show CU traits, and vice versa, could lead to effects cancelling out (Frick et al., 2014a; Frick et al., 2014b) or missing the nuance of how these different difficulties interact in individuals' lives. Accordingly, this research suggests that resilience is not predicted in the same way for everyone and suggests a need for research into whether resilience is enhanced in different ways for different people. This is an important step in working towards effective and personalised treatment for young people with conduct problems and/or callous-unemotional traits. 
SOCIAL FUNCTIONING \& RESLIENCE IN YOUNG PEOPLE

\section{References}

American Psychiatric Association. (2013). Diagnostic and statistical manual of mental disorders (5th ed.). https://doi.org/10.1176/appi.books.9780890425596.

Andrade, B. F., Sorge, G. B., Djordjevic, D., \& Naber, A. R. (2015). Callous-unemotional traits influence the severity of peer problems in children with impulsive/overactive and oppositional/defiant behaviors. Journal of Child and Family Studies, 24(8), 2183-2190. https://doi.org/10.1007/s10826-014-0021-6.

Anyan, F., \& Hjemdal, O. (2016). Adolescent stress and symptoms of anxiety and depression: Resilience explains and differentiates the relationships. Journal of Affective Disorders, 203, 213-220. https://doi.org/10.1016/j.jad.2016.05.031.

Arslan, G. (2018). Social exclusion, social support and psychological wellbeing at school: A study of mediation and moderation effect. Child Indicators Research, 11(3), 897-918. https://doi.org/10.1007/s12187-017-9451-1

Backman, H., Laajasalo, T., Jokela, M., \& Aronen, E. T. (2018). Interpersonal relationships as protective and risk factors for psychopathy: A follow-up study in adolescent offenders. Journal of Youth and Adolescence, 47(5), 1022-1036. https://doi.org/10.1007/s10964-017-0745-X.

Bevilacqua, L., Hale, D., Barker, E. D., \& Viner, R. (2018). Conduct problems trajectories and psychosocial outcomes: A systematic review and meta-analysis. European Child and Adolescent Psychiatry, 27(10), 1239-1260. https://doi.org/10.1007/s00787-0171053-4.

Bijstra, J. O., Bosma, H. A., \& Jackson, S. (1994). The relationship between social skills and psycho-social functioning in early adolescence. Personality and Individual Differences, 16(5), 767-776. https://doi.org/10.1016/0191-8869(94)90218-6. 
SOCIAL FUNCTIONING \& RESLIENCE IN YOUNG PEOPLE

Boden, J. M., Sanders, J., Munford, R., \& Liebenberg, L. (2018). The same but different? Applicability of a general resilience model to understand a population of vulnerable youth. Child Indicators Research, 11(1), 79-96. https://doi.org/10.1007/s12187-0169422-y.

Chrysikou, E. G., \& Thompson, W. J. (2016). Assessing cognitive and affective empathy through the Interpersonal Reactivity Index: An argument against a two-factor model. Assessment, 23(6), 769-777. https://doi.org/10.1177/1073191115599055.

Cicchetti, D. (2013). Annual research review: Resilient functioning in maltreated children Past, present, and future perspectives. Journal of Child Psychology and Psychiatry and Allied Disciplines, 54(4), 402-422. https://doi.org/10.1111/j.1469-7610.2012.02608.x

Criss, M. M., Pettit, G. S., Bates, J. E., Dodge, K. A., \& Lapp, A. L. (2002). Family adversity, positive peer relationships, and children's externalizing behavior: A longitudinal perspective on risk and resilience. Child Development, 73(4), 1220-1237. https://doi.org/10.1111/1467-8624.00468.

Davis, M. H. (1980). A multidimensional approach to individual differences in empathy.

Davis, M. H. (1983). Measuring individual differences in empathy: Evidence for a multidimensional approach. Journal of Personality and Social Psychology, 44, 113-126.

Deault, L. C. (2010). A Systematic review of parenting in relation to the development of comorbidities and functional impairments in children with attention-deficit/ hyperactivity disorder (ADHD). Child Psychiatry Human Development, 41, 168-192. https://doi.org/10.1007/s10578-009-0159-4.

Dick, D. M., Viken, R. J., Kaprio, J., Pulkkinen, L., \& Rose, R. J. (2005). Understanding the covariation among childhood externalizing symptoms: Genetic and environmental influences on conduct disorder, attention deficit hyperactivity disorder, and oppositional 
SOCIAL FUNCTIONING \& RESLIENCE IN YOUNG PEOPLE

defiant disorder symptoms. Journal of Abnormal Child Psychology, 33(2), 219-229. https://doi.org/10.1007/s10802-005-1829-8.

Dodge, K. A., \& Pettit, G. S. (2003). A biopsychosocial model of the development of chronic conduct problems in adolescence. Developmental Psychology, 39(2), 349-371.

Dray, J., Bowman, J., Campbell, E., Freund, M., Wolfenden, L., Hodder, R. K., McElwaine, K., Tremain, D., Bartlem, K., Bailey, J., Small, T., Palazzi, K., Oldmeadow, C., \& Wiggers, J. (2017). Systematic review of universal resilience-focused interventions targeting child and adolescent mental health in the school setting. Journal of the American Academy of Child and Adolescent Psychiatry, 56(10), 813-824. https://doi.org/10.1016/j.jaac.2017.07.780.

Egan, V., \& Bull, S. (2020). Social support does not moderate the relationship between personality and risk-taking / antisocial behaviour. Personality and Individual Differences, 163, 110053. https://doi.org/10.1016/j.paid.2020.110053.

Eisenbarth, H., Demetriou, C. A., Kyranides, N. M., \& Fanti, K. A. (2016). Stability subtypes of callous-unemotional traits and conduct disorder symptoms and their correlates. Journal of Youth and Adolescence, 45, 1889-1901. https://doi.org/10.1007/s10964-0160520-4.

Engels, R. C. M. E., Finkenauer, C., Meeus, W., \& Dekovic, M. (2001). Parental attachment and adolescents' emotional adjustment: The associations with social skills and relational competence. Journal of Counseling Psychology, 48(4), 428-439.

https://doi.org/10.1037/0022-0167.48.4.428.

Fairchild, G., Hawes, D. J., Frick, P. J., Copeland, W. E., Odgers, C. L., Franke, B., Freitag, C. M., \& De Brito, S. A. (2019). Conduct disorder. Nature Reviews Disease Primers, 5(1), 1-25. https://doi.org/10.1038/s41572-019-0095-y. 
Fanti, K. A. (2013). Individual, social, and behavioral factors associated with co-occurring conduct problems and callous-unemotional traits. Journal Abnormal Child Psychology, 41, 811-824. https://doi.org/10.1007/s10802-013-9726-z.

Fanti, K. A., Colins, O. F., Andershed, H., \& Sikki, M. (2017). Stability and change in callous-unemotional traits: Longitudinal associations with potential individual and contextual risk and protective factors. American Journal of Orthopsychiatry, 87(1), 62 75. https://doi.org/10.1037/ort0000143.

Fanti, K. A., Demetriou, C. A., \& Kimonis, E. R. (2013). Variants of callous-unemotional conduct problems in a community sample of adolescents. Journal of Youth and Adolescence, 42, 964-979. https://doi.org/10.1007/s10964-013-9958-9.

Fanti, K. A., Panayiotou, G., Lazarou, C., Michael, R., \& Georgiou, G. (2015). The better of two evils? Evidence that children exhibiting continuous conduct problems high or low on callous-unemotional traits score on opposite directions on physiological and behavioral measures of fear. Development and Psychopathology, 28(1), 185-198. https://doi.org/10.1017/S0954579415000371.

Fergusson, D. M., Horwood, L. J., \& Ridder, E. M. (2005). Show me the child at seven: The consequences of conduct problems in childhood for psychosocial functioning in adulthood. Journal of Child Psychology and Psychiatry and Allied Disciplines, 46(8), 837-849. https://doi.org/10.1111/j.1469-7610.2004.00387.x.

Fontaine, N. M. G., Hanscombe, K. B., Berg, M. T., McCrory, E. J., \& Viding, E. (2018). Trajectories of callous-unemotional traits in childhood predict different forms of peer victimization in adolescence. Journal of Clinical Child and Adolescent Psychology, 47(3), 458-466. https://doi.org/10.1080/15374416.2015.1105139.

Fontaine, N. M. G., McCrory, E. J. P., Boivin, M., Moffitt, T. E., \& Viding, E. (2011). Predictors and outcomes of joint trajectories of callous-unemotional traits and conduct 
SOCIAL FUNCTIONING \& RESLIENCE IN YOUNG PEOPLE

problems in childhood. Journal of Abnormal Psychology, 120(3), 730-742. https://doi.org/10.1037/a0022620.

Forehand, R., Wierson, M., Frame, C., Kempton, T., \& Armistead, L. (1991). Juvenile delinquency entry and persistence: Do attention problems contribute to conduct problems? Journal of Behaviour \& Experimental Psychiatry, 22(4), 261-264.

Frick, P. J. (2003). The Inventory of Callous-Unemotional Traits. University of New Orleans. Frick, P. J., \& Kemp, E. C. (2020). Conduct disorders and empathy development. Annual Reviews of Clinical Psychology, 17, 1-26.

Frick, P. J., \& White, S. F. (2008). Research review: The importance of callous-unemotional traits for developmental models of aggressive and antisocial behavior. Journal of Child Psychology and Psychiatry and Allied Disciplines, 49(4), 359-375.

https://doi.org/10.1111/j.1469-7610.2007.01862.x.

Frick, P. J., Ray, J. V., Thornton, L. C., \& Kahn, R. E. (2014a). Annual research review: A developmental psychopathology approach to understanding callous-unemotional traits in children and adolescents with serious conduct problems. Journal of Child Psychology and Psychiatry, 55(6), 532-548. https://doi.org/10.1111/jcpp.12152.

Frick, P. J., Ray, J. V., Thornton, L. C., \& Kahn, R. E. (2014b). Can callous-unemotional traits enhance the understanding, diagnosis, and treatment of serious conduct problems in children and adolescents? A comprehensive review. Psychological Bulletin, 140(1), 1-57. https://doi.org/10.1037/a0033076.

Frick, P. J., Stickle, T. R., Dandreaux, D. M., Farrell, J. M., \& Kimonis, E. R. (2005). Callous-unemotional traits in predicting the severity and stability of conduct problems and delinquency. Journal of Abnormal Child Psychology, 33(4), 471-487. https://doi.org/10.1007/s10648-005-5728-9. 
Gartland, D., Riggs, E., Muyeen, S., Giallo, R., Afifi, T. O., Macmillan, H., Herrman, H., Bulford, E., \& Brown, S. J. (2019). What factors are associated with resilient outcomes in children exposed to social adversity? A systematic review. BMJ Open, 9(4), 1-14. https://doi.org/10.1136/bmjopen-2018-024870.

Goodman, R., Meltzer, H., \& Bailey, V. (1998). The strengths and difficulties questionnaire: A pilot study on the validity of the self-report version. European Child \& Adolescent Psychiatry, 7(3), 125-130. https://doi.org/10.1007/s007870050057.

Gutman, L. M., Joshi, H., \& Schoon, I. (2019). Developmental trajectories of conduct problems and cumulative risk from early childhood to adolescence. Journal of Youth and Adolescence, 48(2), 181-198. https://doi.org/10.1007/s10964-018-0971-x.

Haas, S. M., Becker, S. P., Epstein, J. N., \& Frick, P. J. (2018). Callous-unemotional traits are uniquely associated with poorer peer functioning in school-aged children. Journal of Abnormal Child Psychology, 46(4), 781-793. https://doi.org/10.1007/s10802-017$\underline{0330-5 .}$

Hammerton, G., Edwards, A. C., Mahedy, L., Murray, J., Maughan, B., Kendler, K. S., Hickman, M., \& Heron, J. (2019). Externalising pathways to alcohol-related problems in emerging adulthood. Journal of Child Psychology and Psychiatry and Allied Disciplines, 6, 721-731. https://doi.org/10.1111/jcpp.13167.

Hawes, D. J., Price, M. J., \& Dadds, M. R. (2014). Callous-unemotional traits and the treatment of conduct problems in childhood and adolescence: A comprehensive review. Clinical Child and Family Psychology Review, 17, 248-267. https://doi.org/10.1007/s10567-014-0167-1.

Herrman, H., Stewart, D. E., Diaz-Granados, N., Berger, E. L., Jackson, B., \& Yuen, T. (2011). What is resilience? La Revue Canadienne de Psychiatrie, 56(5). https://doi/pdf/10.1177/070674371105600504. 
Hjemdal, O., Friborg, O., Stiles, T. C., Rosenvinge, J. H., \& Martinussen, M. (2006). Resilience predicting psychiatric symptoms: A prospective study of protective factors and their role in adjustment to stressful life events. Clinical Psychology and Psychotherapy, 13(3), 194-201. https://doi.org/10.1002/cpp.488.

Hjemdal, O., Vogel, P. A., Solem, S., Hagen, K., \& Stiles, T. C. (2011). The relationship between resilience and levels of anxiety, depression, and obsessive-compulsive symptoms in adolescents. Clinical Psychology \& Psychotherapy, 18(4), 314-321. https://doi.org/10.1002/cpp.719.

Hooper, D., Coughlan, J., \& Mullen, M. (2008). Structural equation modelling: Guidelines for determining model fit. Electronic Journal of Business Research Methods, 6(1), 5360. https://doi.org/10.21427/D79B73.

Hopkins, K. D., Taylor, C. L., \& Zubrick, S. R. (2018). Psychosocial resilience and vulnerability in Western Australian aboriginal youth. Child Abuse and Neglect, 78, 8595. https://doi.org/10.1016/j.chiabu.2017.11.014.

Hopkins, K. D., Zubrick, S. R., \& Taylor, C. L. (2014). Resilience amongst Australian Aboriginal youth: An ecological analysis of factors associated with psychosocial functioning in high and low family risk contexts. PLoS One, 9(7), e102820. https://doi.org/10.1371/journal.pone.0102820.

Kauten, R., Barry, C. T., \& Leachman, L. (2013). Do perceived social stress and resilience influence the effects of psychopathy-linked narcissism and CU traits on adolescent aggression? Aggressive Behavior, 39(5), 381-390. https://doi.org/10.1002/ab.21483.

Khanlou, N., \& Wray, R. (2014). A whole community approach toward child and youth resilience promotion: A review of resilience literature. International Journal of Mental Health \& Addiction, 12, 64-79. https://doi.org/10.1007/s11469-013-9470-1. 
Klibert, J., Lamis, D. A., Collins, W., Smalley, K. B., Warren, J. C., Yancey, C. T., \& Winterowd, C. (2014). Resilience mediates the relations between perfectionism and college student distress. Journal of Counseling and Development, 92(1), 75-82. https://doi.org/10.1002/j.1556-6676.2014.00132.x.

Klingzell, I., Fanti, K. A., Olivier, C. F., Frogner, L., Andershed, A.K., \& Andershed, H. (2016). Early childhood trajectories of conduct problems and callous-unemotional traits: The role of fearlessness and psychopathic personality dimensions. Child Psychiatry \& Human Development, 47, 236-247. https://doi.org/10.1007/s10578-015-0560-0

Liebenberg, L., Ungar, M., \& LeBlanc, J. C. (2013). The CYRM-12: A brief measure of resilience. Canadian Journal of Public Health, 104(2), 131-135.

Liu, J. J. W., Reed, M., \& Girard, T. A. (2017). Advancing resilience: An integrative, multisystem model of resilience. Personality and Individual Differences, 111, 111-118. https://doi.org/10.1016/j.paid.2017.02.007.

Loeber, R., \& Burke, J. D. (2011). Developmental pathways in juvenile externalizing and internalizing problems. Journal of Research on Adolescence, 21(1), 34-46. https://doi.org/10.1111/j.1532-7795.2010.00713.x.

Luthar, S. S., \& Cicchetti, D. (2000). The construct of resilience: Implications for interventions and social policies. Development and Psychopathology, 12(4), 857-885. https://doi.org/10.1017/S0954579400004156.

Luthar, S. S., Cicchetti, D., \& Becker, B. (2000). The construct of resilience: A critical evaluation and guidelines for future work. Child Development, 71(3), 543-562. https://doi.org/10.1111/1467-8624.00164.

Lyneham, H. J., Street, A. K., Abbott, M. J., \& Rapee, R. M. (2008). Psychometric properties of the school anxiety scale-Teacher report (SAS-TR). Journal of Anxiety Disorders, 22(2), 292-300. https://doi.org/10.1016/j.janxdis.2007.02.001. 
Miron, C. D., Satlof-Bedrick, E., \& Waller, R. (2020). Longitudinal association between callous-unemotional traits and friendship quality among adjudicated adolescents. Journal of Adolescence, 81, 19-26. https://doi.org/10.1016/j.adolescence.2020.03.010.

Muñoz, L. C., Kerr, M., \& Besic, N. (2008). The peer relationships of youths with psychopathic personality traits: A matter of perspective. Criminal Justice and Behavior, 35(2), 212-227. https://doi.org/10.1177/0093854807310159.

Nantel-Vivier, A., Pihl, R. O., Côté, S., \& Tremblay, R. E. (2014). Developmental association of prosocial behaviour with aggression, anxiety and depression from infancy to preadolescence. Journal of Child Psychology and Psychiatry, 55(10), 11351144. https://doi.org/10.1111/jcpp.12235.

Nilsen, W., Karevold, E., Røysamb, E., Gustavson, K., \& Mathiesen, K. S. (2013). Social skills and depressive symptoms across adolescence: Social support as a mediator in girls versus boys. Journal of Adolescence, 36, 11-20. https://doi.org/10.1016/j.adolescence.2012.08.005.

Pardini, D. A., \& Fite, P. J. (2010). Symptoms of conduct disorder, oppositional defiant disorder, attention-deficit/hyperactivity disorder, and callous-unemotional traits as unique predictors of psychosocial maladjustment in boys: Advancing an evidence base for DSM-V. Journal of the American Academy of Child and Adolescent Psychiatry, 49(11), 1134-1144. https://doi.org/10.1016/j.jaac.2010.07.010.

Piatigorsky, A., \& Hinshaw, S. P. (2004). Psychopathic traits in boys with and without attention-deficit/ hyperactivity disorder: Concurrent and longitudinal correlates. Journal of Abnormal Child Psychology, 32(5), 535-550. https://doi.org/10.1023/B:JACP.0000037782.28482.6b.

Ray, J. V., \& Frick, P. J. (2020). Assessing callous-unemotional traits using the total score from the Inventory of Callous-Unemotional Traits: A meta-analysis. Journal of Clinical 
SOCIAL FUNCTIONING \& RESLIENCE IN YOUNG PEOPLE

Child and Adolescent Psychology, 49(2), 190-199.

https://doi.org/10.1080/15374416.2018.1504297.

Renbarger, R. L., Padgett, R. N., Cowden, R. G., Govender, K., Yilmaz, M. Z., Scott, L. M., ... Křeménková, L. (2020). Culturally relevant resilience: A psychometric meta-analysis of the Child and Youth Resilience Measure (CYRM). Journal of Research on Adolescence, 30(4), 896-912. https://doi.org/10.1111/jora.12569.

Robertson, E. L., Frick, P. J., Ray, J. V., Thornton, L. C., Wall Myers, T. D., Steinberg, L., \& Cauffman, E. (2020). Do callous-unemotional traits moderate the effects of the juvenile justice system on later offending behavior? Journal of Child Psychology and Psychiatry. https://doi.org/10.1111/jepp.13266.

Rowe, R., Costello, J., Angold, A., Copeland, W. E., \& Maughan, B. (2010). Developmental pathways in oppositional defiant disorder and conduct disorder. Journal of Abnormal Psychology, 119(4), 726-738. https://doi.org/10.1037/a0020798.

Rowe, R., Maughan, B., Pickles, A., Costello, E. J., \& Angold, A. (2002). The relationship between DSM-IV oppositional defiant disorder and conduct disorder: Findings from the Great Smoky Mountains Study. Journal of Child Psychology and Psychiatry and Allied Disciplines, 43(3), 365-373. https://doi.org/10.1111/1469-7610.00027.

Russell, B. S., Collins, C. M., Tomkunas, A. J., \& Hutchison, M. (2021). Exploring the factor structure of the child and youth resilience measure (CYRM-12) for young children in a disadvantaged community. Children and Youth Services Review, 120. https://doi.org/10.1016/j.childyouth.2020.105746.

Saunders, M. C., Anckarsäter, H., Lundström, S., Hellner, C., Lichtenstein, P., \& Fontaine, N. M. G. (2019). The associations between callous-unemotional traits and symptoms of conduct problems, hyperactivity and emotional problems: A study of adolescent twins 
screened for neurodevelopmental problems. Journal of Abnormal Child Psychology, 47(3), 447-457. https://doi.org/10.1007/s10802-018-0439-1.

Segrin, C., \& Rynes, K. N. (2009). The mediating role of positive relations with others in associations between depressive symptoms, social skills, and perceived stress. Journal of Research in Personality, 43(6), 962-971. https://doi.org/10.1016/j.jrp.2009.05.012.

Segrin, C., \& Taylor, M. (2007). Positive interpersonal relationships mediate the association between social skills and psychological well-being. Personality and Individual Differences, 43(4), 637-646. https://doi.org/10.1016/j.paid.2007.01.017.

Segrin, C., Hanzal, A., Donnerstein, C., Taylor, M., \& Domschke, T. J. (2007). Social skills, psychological well-being and the mediating role of perceived stress. Anxiety, Stress \& Coping, 20(3), 321-329. https://doi.org/10.1080/10615800701282252.

Segrin, C., Mcnelis, M., \& Swiatkowski, P. (2016). Social skills, social support, and psychological distress: A test of the social skills deficit vulnerability model. Human Communication Research, 42, 122-137. https://doi.org/10.1111/hcre.12070.

Silke, C., Brady, B., Boylan, C., \& Dolan, P. (2018). Factors influencing the development of empathy and pro-social behaviour among adolescents: A systematic review. Children and Youth Services Review, 94, 421-436.

https://doi.org/10.1016/j.childyouth.2018.07.027.

Smetana, J. G., Campione-Barr, N., \& Metzger, A. (2006). Adolescent development in interpersonal and societal contexts. Annual Review of Psychology, 57, 255-284. https://doi.org/10.1146/annurev.psych.57.102904.190124.

Strough, J., Swenson, L. M., \& Cheng, S. (2001). Friendship, gender, and preadolescents ' representations of peer collaboration. Merrill-Palmer Quarterly, 47(4), 475-499.

Takahashi, Y., Pease, C. R., Pingault, J., \& Viding, E. (2020). Genetic and environmental influences on the developmental trajectory of callous-unemotional traits from childhood 
SOCIAL FUNCTIONING \& RESLIENCE IN YOUNG PEOPLE

to adolescence. Journal of Child Psychology and Psychiatry. https://doi.org/10.1111/jepp.13259.

Thornton, L. C., Frick, P. J., Ray, J. V., Wall Myers, T. D., Steinberg, L., \& Cauffman, E. (2019). Risky sex, drugs, sensation seeking, and callous unemotional traits in justiceinvolved male adolescents. Journal of Clinical Child and Adolescent Psychology, 48(1), 68-79. https://doi.org/10.1080/15374416.2017.1399398.

Van Harmelen, A. L., Kievit, R. A., Ioannidis, K., Neufeld, S., Jones, P. B., Bullmore, E., ... Goodyer, I. (2017). Adolescent friendships predict later resilient functioning across psychosocial domains in a healthy community cohort. Psychological Medicine, 47(13), 2312-2322. https://doi.org/10.1017/S0033291717000836.

Van Lier, P. A. C., van der Ende, J., Koot, H. M., \& Verhulst, F. C. (2007). Which better predicts conduct problems? The relationship of trajectories of conduct problems with ODD and ADHD symptoms from childhood into adolescence. Journal of Child Psychology and Psychiatry and Allied Disciplines, 48(6), 601-608. https://doi.org/10.1111/j.1469-7610.2006.01724.x.

Vanderbilt-Adriance, E., Shaw, D. S., Brennan, L. M., Dishion, T. J., Gardner, F., \& Wilson Ella, M. N. (2016). Protective factors in the development of early child conduct problems. Family Relations, 64(1), 64-79. https://doi.org/10.1111/fare.12105.

Vella, S. L. C., \& Nagesh, B. P. (2019). A theoretical review of psychological resilience: Defining resilience and resilience research over the decades. Archives of Medicine and Health Sciences, 7, 233-239. https://doi.org/10.4103/amhs.amhs_119_19.

Viding, E., \& McCrory, E. J. P. (2012). Why should we care about measuring callousunemotional traits in children? The British Journal of Psychiatry, 200, 177-178. https://doi.org/10.1192/bjp.bp.111.099770. 
SOCIAL FUNCTIONING \& RESLIENCE IN YOUNG PEOPLE

Viding, E., Simmonds, E., Petrides, K. V., \& Frederickson, N. (2009). The contribution of callous-unemotional traits and conduct problems to bullying in early adolescence. Journal of Child Psychology and Psychiatry and Allied Disciplines, 50(4), 471-481. https://doi.org/10.1111/j.1469-7610.2008.02012.x.

Vinayak, S., \& Judge, J. (2018). Resilience and empathy as predictors of psychological wellbeing among adolescents. International Journal of Health Sciences \& Research, 8(4), 192-200.

Wall, T. D., Frick, P. J., Fanti, K. A., Kimonis, E. R., \& Lordos, A. (2016). Factors differentiating callous-unemotional children with and without conduct problems. Journal of Child Psychology and Psychiatry, 57(8), 976-983. https://doi.org/10.1111/jcpp.12569.

Waller, R., Hyde, L. W., Baskin-Sommers, A. R., \& Olson, S. L. (2017). Interactions between callous unemotional behaviors and executive function in early childhood predict later aggression and lower peer-liking in late-childhood. Journal of Abnormal Child Psychology, 45(3), 597-609. https://doi.org/10.1007/s10802-016-0184-2.

Waller, R., Wagner, N. J., Barstead, M. G., Subar, A., Petersen, J. L., Hyde, J. S., \& Hyde, L. W. (2020). A meta-analysis of the associations between callous-unemotional traits and empathy, prosociality, and guilt. Clinical Psychology Review, 75. https://doi.org/10.1016/j.cpr.2019.101809.

Waller, R., Wagner, N. J., Flom, M., Ganiban, J., \& Saudino, K. J. (2019). Fearlessness and low social affiliation as unique developmental precursors of callous-unemotional behaviors in preschoolers. Psychological Medicine, 1-9. https://doi.org/10.1017/S003329171900374X.

Waschbusch, D. A., Willoughby, M. T., Haas, S. M., Ridenour, T., Helseth, S., Crum, K. I., Altszuler, A. R., Ross, J. M., Coles, E. K., \& Pelham, W. E. (2019). Effects of 
SOCIAL FUNCTIONING \& RESLIENCE IN YOUNG PEOPLE

behavioral treatment modified to fit children with conduct problems and callousunemotional (CU) traits. Journal of Clinical Child and Adolescent Psychology, 53, 112. Advance online publication. https://doi.org/10.1080/15374416.2019.1614000.

Wilkinson, S., Waller, R., \& Viding, E. (2016). Practitioner Review: Involving young people with callous unemotional traits in treatment - Does it work? A systematic review. Journal of Child Psychology and Psychiatry and Allied Disciplines, 57(5), 552-565. https://doi.org/10.1111/jcpp.12494. 


\section{Appendices}

\section{Appendix A. Collaboration/Co-operation Questionnaire}

\section{(21 items)}

Please think about your learning experiences at school. Answer each statement by circling the number which most reflects how true the statement is for you.

\section{$\begin{array}{lllll}1 & 2 & 3 & 4 & 5\end{array}$}

Almost Never Usually Not True sometimes True/ Usually True Almost always True

1. Schoolwork is fairly easy for me

2. When we work together in small groups, we try to make sure that everyone in the group learns the assigned material

3. I like to work with others

4. Everyone has an equal chance to be successful if they do their best.

5. Other students want me to come to school everyday

6. If a student works hard, he/she can definitely succeed in school

7. My teacher likes to help me learn

8. I have a lot of questions I never get the chance to ask in class.

9. My teachers want me to do the best I can

10. When we work together in small groups, we cannot complete an assignment unless everyone contributes

11. Students get the grades they deserve, no more no less.

12. All students in our year know each other well

13. When we work together in small groups, the teacher divides up the material so that everyone has a part and everyone must share.

14. I learn more from students who are different from me.

15. Sometimes I think the scoring systems in classes are not fair.

16. When we work together in small groups, we have to share materials in order to complete the assignment. 
17. When we work together in small groups, everyone's ideas are needed if we ae going to be successful.

18. When we work together in small groups, I have to find out what everyone else knows if I am going to be able to do the assignment.

19. It is a good idea for students to help each other to learn

20. Students learn a lot of important things from each other

21. I would rather work on schoolwork alone than with other students 


\section{Appendix B. Child and Youth Resilience Measure}

(12 items) CYRM - 12

Using the scale provided, please circle to what extent the sentences below describe you? Circle one answer for each statement.

$\begin{array}{lllll}1 & 2 & 3 & 4 & 5\end{array}$

Not at all A little Somewhat Quite a bit A lot

1. I have people I look up to

2. Getting an education is important to me

3. My parent(s)/caregiver(s) know a lot about me

4. I try to finish what I start

5. I am able to solve problems without harming myself or others (for example by using drugs and/or being violent)

6. I know where to go in my community to get help

7. I feel I belong at my school

8. My family stands by me during difficult times

9. My friends stand by me during difficult times

10. I am treated fairly in my community

11. I have opportunities to develop skills that will be useful later in life (like job skills and skills to care for others)

12. I enjoy my community's traditions $\begin{array}{lllll}1 & 2 & 3 & 4 & 5\end{array}$

$\begin{array}{lllll}1 & 2 & 3 & 4 & 5\end{array}$

$\begin{array}{lllll}1 & 2 & 3 & 4 & 5\end{array}$

$\begin{array}{lllll}1 & 2 & 3 & 4 & 5\end{array}$

$\begin{array}{lllll}1 & 2 & 3 & 4 & 5\end{array}$

$\begin{array}{lllll}1 & 2 & 3 & 4 & 5\end{array}$

$\begin{array}{lllll}1 & 2 & 3 & 4 & 5\end{array}$

$\begin{array}{lllll}1 & 2 & 3 & 4 & 5\end{array}$

$\begin{array}{lllll}1 & 2 & 3 & 4 & 5\end{array}$

$\begin{array}{lllll}1 & 2 & 3 & 4 & 5\end{array}$

$\begin{array}{lllll}1 & 2 & 3 & 4 & 5\end{array}$

$\begin{array}{lllll}1 & 2 & 3 & 4 & 5\end{array}$


SOCIAL FUNCTIONING \& RESLIENCE IN YOUNG PEOPLE 
Appendix C. Information and Opt-Out Form for Parents

\title{
Southampton
}

\author{
PARENT/ GUARDIAN INFORMATION SHEET \\ (Version 2/ 07/09/2015)
}

Study Title: Developing effective learners: Assessing the effectiveness of an education intervention in secondary school pupils

Researcher: \#\#\#\#\#

Ethics number: \#\#\#\#\#

Dear Parent/ Guardian

The \#\#\# School is implementing a new approach to teaching and learning across the school curriculum at Key Stage 3. Its aim is to develop key habits of mind in pupils to facilitate the development of personal (e.g., resilience) and education skills (e.g., creativity and collaborative work) for effective life-long learning. In order to understand the impact of this change in practice it has asked researchers at the University of Southampton to evaluate its effectiveness. This evaluation will involve working with your child at three different time points in the school year and across Years 7 to Year 9.

This development forms a core part of the curriculum and your child's experience of teaching and learning in the \#\#\#\# School. You and your child can decide whether you want them to take part in the evaluation component of this initiative. The aim of this letter is to explain what the evaluation involves and to give you the opportunity to tell the school if you do not want your child to be part of it.

Please read this information carefully before deciding whether or not you want your child to take part in this research project. If you are happy for your child to participate you need not do anything.

If you would like your child to be withdrawn from data collection please return the opt-out form (below) to your child's tutor by September 14, 2015.

What is the study about?

This study is intended to assess the educational intervention implemented by the school and its teachers.

Why is the study important?

The study is important to show the progress of the intervention. The data collected will provide the school with a clearer understanding of what learning outcomes and attitudes have improved and those that require further work.

Why has your child been chosen to take part in the survey? 
Your child has been invited to take part because he or she will be starting the new academic year (September 2015) in Year 7, 8 or 9.

\section{What will happen if your child takes part?}

Involvement in the study requires your child to participate in an online survey to assess key skills for effective education and that can impact learning and educational outcome. Core constructs include measuring skills associated with curiosity, resilience, reflection on teaching and learning, self-management and organisation, creativity, collaborative learning and related empathic skills and worry or anxiety in school. In addition, because we want to understand whether some pupils benefit more from this novel approach to teaching and learning compared with others, we will also ask your child about his or her general behaviour (e.g.,about their relationships with their peers and general conduct). In addition, we will ask the school for records of attendance and achievement and if your child has any special educational needs.

The \#\#\#\# School have asked that we administer the online survey 3 times over the course of the academic year starting September 2015 to July 2016, and for the subsequent two academic years to understand any long term benefits.

We will be able to provide summary results for teachers and parents at the end of each school year.

\section{Are there any benefits in my child taking part?}

The survey will give your child the opportunity to reflect on themselves as a learner. Your child will benefit from knowing they are involved in a survey that considers their habits of mind and that aims to lead to positive change in the way they learn and achieve. We will explain to your child what we are asking them to do and why. In addition, we can show them what has changed over time in their year group and the importance of any change.

\section{Are there any risks involved?}

Our priority is to ensure the wellbeing of your child as a participant. Every effort will be made to ensure that their participation in the study is a positive experience, and that your child remains happy to complete the survey over the course of the year. Although we have deemed the survey to be low risk, there is always the possibility that some young people might experience increased worry whilst taking part in the survey. If your child experiences any discomfort, they will be free to stop the survey. In addition, we would encourage them to discuss any negative feelings with you or another supportive adult (e.g., a member of staff in school).

\section{Will our participation be confidential?}

Yes. All participants will be assigned identification numbers, so that information stored within electronic data files will anonymised.

\section{What happens if we change our minds?}

You and your child are fully entitled to change your mind and you can withdraw from the study at any point without your legal rights being affected.

\section{What happens if something goes wrong?}


In the unlikely event that you feel that you have been placed at risk, you can contact the Chair of the Ethics Committee at the University of Southampton: Phone: +44 (0)238059 3856, email fshs-rso@soton.ac.uk.

\section{Where can we get more information?}

If you have any questions about the study after reading this information sheet, please contact \#\#\#\#\# at the University of Southampton. Telephone \#\#\#\#\#\#, email: \#\#\#\#\# 


\section{OPT-OUT CONSENT FORM}

(Version 2/ 07/09/2015)

Study Title: Developing effective learners: Assessing the effectiveness of an education intervention in secondary school pupils

Researcher:

Ethics number:

If you would like your child to be withdrawn from data collection please return the opt-out form (below) to your child's tutor by September 14, 2015.

Please initial the boxes to indicate that you agree with the statements

I do not wish for my child to take part in the online surveys

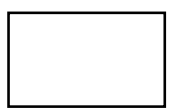

I understand that the school will arrange an alternative task whilst the surveys take place

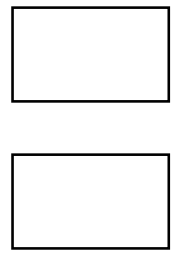

I have read and understood the Participant Information Sheet (Version Number $207 / 09 / 2015$ ) and I have had the opportunity to ask questions about the study

If you would like to give reason why your child should not take part please use the space provided below:

We would like to thank you again for your time and consideration of the study

Name (print name).

Childs Name (print name)

Child's tutor group

Contact Phone Number

Contact Email Address (optional)

Signature.

Date. 


\section{Appendix D. Standardised Instructions for Staff to Read to the Student's Pre-}

\section{Assessment}

\section{(Version 1/ 28/08/2015)}

- We want to find out some information about you and your experiences in school using an online survey.

- You do not have to enter your name onto the survey, only your student number.

- If you have any questions about the survey please raise your hand now (wait). If you have any questions during the survey the you can put your hand up and we will come and see you.

- We can help with basic questions, but can't answer the questions for you.

- You don't have to do the survey. You can say that you don't want to do it and there won't be any consequences.

- Please raise your hand if you don't want to do the survey. (Wait for any responses.)

- If you wish to stop at any point, then put your hand up we will come and help you log off.

- You have all been provided with a set of instructions, in front of your computer, which you must read and follow.

- Please do not look at the persons screen next to you.

- Remember there are no right or wrong answers.

- And please try to answers questions as truthfully as possible

Thank you for listening, you may now start from the instructions provided 
SOCIAL FUNCTIONING \& RESLIENCE IN YOUNG PEOPLE

\section{Appendix E. Students Survey Preamble}

\section{$\underline{\text { Standardised Instructions for Students }}$}

\section{$\underline{\text { (Version 1. 28/08/2015) }}$}

Pupils will load up a web-browsing window and type in the webpage for the iSurvey. They will see the following instructions:

You will be taken through a series of questions and tasks. Please work your way through these. It should take around 30 to 40 minutes to complete.

Remember, try to answer the questions truthfully. And there are no right or wrong answers.

Press the space bar to start.

Consent form

Start the survey. 


\section{Appendix F. Student Consent Form}

(Version Number 01, 28/08/2015)

Study title: Developing effective learners: Assessing the effectiveness of an education intervention in secondary school pupils

Researcher name: \#\#\#\#\#

ERGO Study ID number: \#\#\#\#\#

\section{Please tick the box(es) if you agree with the sentences below:}

I understand that my parent has given permission for

me to take part in this study

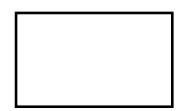

I understand that I can agree or disagree to take part in the study and that nobody will be upset or disappointed if I decide that I don't want to take part

I understand that I can decide not to take part even if my parent or carer has given their permission for me to take part
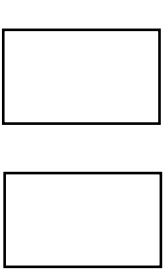

My parent/carer or teacher has talked with me about the study and whether or not I would like to take part

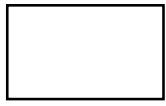

I have had the chance to ask questions about the study and talk about anything that is worrying me about taking part

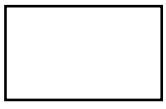

I understand that my data will be stored safely to keep it private

I understand that it will not be possible for anybody reading the research report to be able to tell that I took part in this study
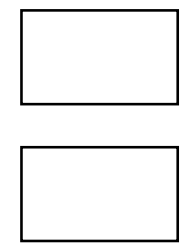

I understand that I can change my mind or decide to stop taking part in the study at any time, without needing to give a reason

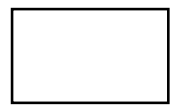

I agree to take part in this study

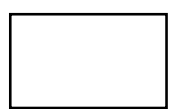

Name of participant (print name)

Signature of participant.

Date. 
Appendix G. Debrief Form

Developing effective learners: Assessing the effectiveness of an education intervention in secondary school pupils

(Version 1. 28/08/2015)

The \#\#\# School is working to help its pupils develop better learning skills in school and throughout your future careers.

They wanted to know if the changes they are planning to make in school will make you better learners. So they asked us to think about what questions are important to understand whether the change in approach to teaching in school will mean that you as learners develop better skills in e.g., thinking about your learning, working with and understanding others or trying to find out new things.

We also wanted to understand if worry in school or your behaviour more generally might influence how well you can learn new skills.

There were no right or wrong answers in any of the questions we asked or the tasks you did.

The information you have gave us will help us to understand how we can make teaching and learning better for pupils, so that they really enjoy learning and being in school.

This information may be then used by other schools to help pupils learn and develop in during their secondary education and beyond.

We will not include your name in the study and no-one except the researchers and some teachers in the school will look at your answers.

\section{Do you have any questions?}

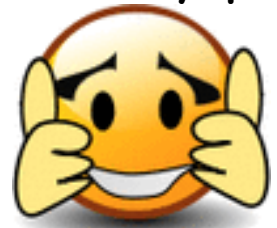

THANKS FOR HELPING US. 


\section{Appendix H. Ethical Considerations}

Ethical approval of this study was granted by the University of Southampton's Ethics Committee on the 14/09/2015 and all researchers were involved in the submission of this application. The study was deemed to be low risk, as data collection was carried out in a safe and known environment to the adolescents. All data collected was anonymised and stored on secure, password protected computers. Participants and their parents/guardians were informed of this prior to data collection and were advised that they may withdraw their data without consequence. In order to maximise participants' positive mood after completing the survey, two rateable jokes were presented at the end.

A risk assessment highlighted three main hazards for participants; a) a participant becoming upset or anxious during survey administration, b) participant becoming bored or restless during survey administration, c) heightened risk of seizure or other medical condition due to prolonged computer use. One main risk was identified for teaching staff administering the survey, d) student becoming physically or verbally aggressive during administration. These risks were controlled for accordingly:

a) Any student who becomes upset has the opportunity to discuss their feelings with familiar teaching staff present or any student may speak with the school counsellor. It was also highlighted that participants could withdraw at any time, without consequence.

b) The survey was designed with a break opportunity and Guilford's Alternative Use's Task was used as a measure of creativity which provided a break from reading and answering self-report measures.

c) Staff will be present during administration and the school will have procedures in place for such an incident. As a preventative measure, parents/guardians were informed of the survey length and need for participants to look at a computer screen for an extended period of time (approx. 1 hour) in the information and parent/guardian consent form. It was 
recommended for any student at risk of seizures, or other medical condition exacerbated by prolonged computer use, to be withdrawn from the study before commencement of data collection.

d) Teaching staff will be familiar with their students and the school will have procedures in place for any negative behaviour related incidents. 
SOCIAL FUNCTIONING \& RESLIENCE IN YOUNG PEOPLE

\section{Appendix I. Comparison of Model 1 and Model $2 R^{2}$ For Groups}

\section{Table 6}

Comparison of $R^{2}$ Values Across Groups for Both Model 1 and Model 2 and Between Model 1 and Model

\begin{tabular}{|c|c|c|c|c|c|}
\hline \multirow[b]{2}{*}{ Variable } & \multicolumn{4}{|c|}{ Z score } & \multirow{2}{*}{$\begin{array}{c}\text { Model } 1 \text { vs } \\
\text { Model } 2\end{array}$} \\
\hline & $\mathrm{L}_{\mathrm{CU}} \mathrm{L}_{\mathrm{CP}}$ & $\mathrm{H}_{\mathrm{CU}} \mathrm{L}_{\mathrm{CP}}$ & $\mathrm{L}_{\mathrm{CU}} \mathrm{H}_{\mathrm{CP}}$ & $\mathrm{H}_{\mathrm{CU}} \mathrm{H}_{\mathrm{CP}}$ & \\
\hline $\mathrm{LCU}_{\mathrm{CP}}$ & & -0.06 & 0.12 & 0.03 & 0.00 \\
\hline $\mathrm{H}_{\mathrm{CU}} \mathrm{L}_{\mathrm{CP}}$ & -0.07 & & 0.17 & 0.09 & 0.01 \\
\hline $\mathrm{L}_{\mathrm{CU}} \mathrm{H}_{\mathrm{CP}}$ & 0.08 & 0.15 & & -0.09 & 0.04 \\
\hline $\mathrm{H}_{\mathrm{CU}} \mathrm{H}_{\mathrm{CP}}$ & 0.00 & 0.07 & -0.07 & & 0.03 \\
\hline
\end{tabular}

Note. $\mathrm{Z}$ values at the top of the table are for Model $1, \mathrm{Z}$ values at the bottom of the diagonal, shaded in grey, are for Model 2. Model 2 differs from Model 1 by the addition of Gender and Year Group as predictors. The final column is for comparing Model $1 R^{2}$ scores for each group to Model 2 scores for each group. * indicates a significant $\mathrm{Z}$ score. Z scores above 1.96 are significant at 5\%, z scores below 1.96 are not significant. None of the above $\mathrm{Z}$ scores were significant 